PRX62 and PRX69 regulate RH growth at low-temperature

\title{
Apoplastic class III peroxidases PRX62 and PRX69 regulate ROS-homeostasis and cell wall associated extensins linked to root hair growth at low-temperature in Arabidopsis thaliana
}

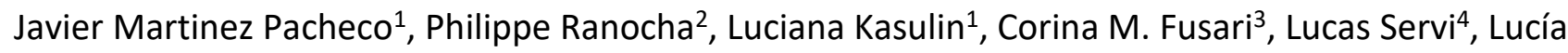
Ferrero ${ }^{5}$, Victoria Berdion Gabarain ${ }^{1}$, Juan Manuel Peralta ${ }^{1}$, Cecilia Borassi ${ }^{1}$, Eliana Marzol ${ }^{1}$, Diana

Rosa Rodríguez-Garcia ${ }^{1}$, Yossmayer del Carmen Rondón Guerrero ${ }^{1}$, Mariana Carignani Sardoy ${ }^{1}$, Javier Botto ${ }^{6}$, Claudio Meneses ${ }^{7}$, Federico Ariel ${ }^{5}$, Ezequiel Petrillo ${ }^{4}$, Christophe Dunand ${ }^{2}$ \& José M. Estevez ${ }^{1,7,+}$

${ }^{1}$ Fundación Instituto Leloir and IIBBA-CONICET. Av. Patricias Argentinas 435, Buenos Aires C1405BWE, Argentina.

2Université de Toulouse, UPS, UMR 5546, Laboratoire de Recherche en Sciences Végétales, Université de Toulouse, CNRS, UPS, Toulouse INP, 31326, Castanet-Tolosan, France.

${ }^{3}$ Centro de Estudios Fotosintéticos y Bioquímicos, Universidad Nacional de Rosario, 2000, Rosario, Santa Fe, Argentina.

${ }^{4}$ Instituto de Fisiología, Biología Molecular y Neurociencias (IFIBYNE-UBA-CONICET) and Facultad de Ciencias Exactas y Naturales, Universidad de Buenos Aires, Ciudad Universitaria, Buenos Aires, Argentina.

${ }^{5}$ Instituto de Agrobiotecnología del Litoral, Universidad Nacional del Litoral, CONICET, FBCB, Centro Científico Tecnológico CONICET Santa Fe, Colectora Ruta Nacional No 168 km. 0, Paraje El Pozo, Santa Fe 3000, Argentina

6IFEVA, UBA, CONICET, Facultad de Agronomía, Universidad de Buenos Aires, C1417DSE Ciudad Autónoma de Buenos Aires, Argentina botto@agro.uba.ar.

${ }^{7}$ Centro de Biotecnología Vegetal, Facultad de Ciencias de la Vida, Universidad Andres Bello and ANID - Millennium Science Initiative Program - Millennium Institute for Integrative Biology (iBio), Santiago, Chile.

†Correspondence should be addressed. Email: jestevez@leloir.org.ar / jose.estevez@unab.cl (J.M.E).

Word count: 6,716 
PRX62 and PRX69 regulate RH growth at low-temperature

\section{ABSTRACT}

Root Hairs (RHs) growth is highly influenced by endogenous as well as by external environmental signals that coordinately regulate its final cell size. RHs actively expand the root surface responsible for nutrient uptake and water absorption. We have recently determined that RH growth was unexpectedly boosted when Arabidopsis thaliana seedlings are cultivated at low temperatures. It was proposed that $\mathrm{RH}$ growth plasticity in response to low temperature was linked to a reduced nutrient availability in the media. Here, we explored the molecular basis of this strong $\mathrm{RH}$ growth response by using the Genome Wide Association Studies (GWAS) approach on Arabidopsis thaliana natural accessions. We identified the poorly characterized PEROXIDASE 62 (PRX62) as a key protein triggering this conditional growth under a moderate low-temperature stress. In addition, we identified the related protein PRX69 as an important factor in this developmental process. The prx62 prx69 double mutant and the PRX62 and PRX69 over-expressing lines showed contrasting RH phenotypes, peroxidase activities and cyt/apoReactive Oxygen Species (ROS) levels. Strikingly, a cell wall protein extensin (EXT) reporter revealed the effect of peroxidase activity on the EXT cell wall association at $10^{\circ} \mathrm{C}$ in the $\mathrm{RH}$ apical zone. EXT cell wall insolubilization was enhanced at $10^{\circ} \mathrm{C}$, which was completely abolished under the PRX inhibitor salicylhydroxamic acid (SHAM) treatment. Finally, we demonstrated that the Root Hair defective 6-like 4 (RSL4) bHLH family transcription factor directly controls the expression of PRX69. Collectively, our results indicate that both PRX62 and PRX69 are key apoplastic PRXs that modulate ROS-homeostasis and cell wall EXT-insolubilization linked to RH elongation at low-temperature.

Key words: Arabidopsis, Class-III Peroxidases, Extensins, Genome Wide Association Studies, Lowtemperature, RSL4, ROS-homeostasis.

Word count: 258 
PRX62 and PRX69 regulate RH growth at low-temperature

\section{INTRODUCTION}

Root hairs $(\mathrm{RH})$ have emerged as an excellent model system for studying cell size regulation since they can elongate several hundred-fold their original dimensions. The rate at which cells grow is determined both by cell-intrinsic factors as well as by external environment signals. RHs represent an important proportion of the surface root area, crucial for nutrient uptake and water absorption. $\mathrm{RH}$ growth is controlled by the interaction of several proteins, including the bHLH transcription factor (TF) RSL4 (Root Hair Defective Six-like 4), which defines the final RH length (Datta et al. 2015; Mangano et al. 2017) as well as the related TF RSL2 (Root Hair Defective 6 Six-like 2; Bhosale et al. 2018; Mangano et al. 2018). Together with the developmental and genetic pathways, several hormones are important modulators of RH cell growth (Lee \& Cho 2013; Velasquez et al. 2016; Zhang et al 2016; Mangano et al. 2017). In addition, abnormal Reactive Oxygen Species (ROS) accumulation in $\mathrm{RHs}$ triggers either exacerbated growth or cell bursting. Exogenous $\mathrm{H}_{2} \mathrm{O}_{2}$ inhibited $\mathrm{RH}$ polar expansion, while treatment with ROS scavengers (e.g., ascorbic acid) caused RH bursting, reinforcing the notion that a balanced ROS-homeostasis is required to modulate cell elongation by affecting cell wall properties. Accordingly, apoplastic ROS (apoROS) produced in the apoplast (specifically apo $\mathrm{H}_{2} \mathrm{O}_{2}$ ) coupled to apoplastic Class III peroxidase (PRX) activity directly affect the degree of cell wall crosslinking (Passardi et al. 2004) by oxidizing cell wall compounds and leading to the stiffening of the wall in peroxidative cycles (PC) (Orman-Ligeza et al. 2016). In addition, apoROS coupled to PRX activity enhances non-enzymatic wall loosening by producing oxygen radical species (e.g., ${ }^{\bullet} \mathrm{OH}$ ) and promoting polar-growth in hydroxylic cycles (HC) (Dunand et al. 2007). Finally, PRXs also contribute to the production of superoxide radical $\left(\mathrm{O}_{2}{ }^{\bullet-}\right)$ pool together with NADPH oxidase/respiratory burst oxidase homolog $(\mathrm{RBOH})$ proteins by oxidizing singlet oxygen in the oxidative cycle $(\mathrm{OC})$, thereby affecting apo $\mathrm{H}_{2} \mathrm{O}_{2}$ levels. Given their multiple enzymatic activities in vivo, apoplastic PRXs emerge as versatile regulators of rapid cell elongation. Assigning specific functions to each of the numerous PRXs (73 encoded in Arabidopsis; Valerio et al. 2004; and even more in other plant types, e.g. 138 encoded in Rice; Passardi et al. 2004a) has been challenging. Recently, three PRXs possibly linked to Tyrcrosslinking of cell wall extensins (EXTs), PRX01, PRX44 and PRX73, were characterized as important regulators of $\mathrm{RH}$ growth under low-nutrient conditions (Marzol et al. 2021). These RH specific PRXs are under the direct control of the TF RSL4, a master regulator of RH cell size (Yi et al. 2010; Datta et al. 2015; Mangano et al. 2017). In addition, other PRXs were postulated to crosslink EXTs in aerial plant tissues. PRX09 and PRX40 were proposed to crosslink EXTs during tapetum development, and both, PRXs were able to crosslink EXT23 in transient expression experiments (Jacobowitz et al. 2019).

Although there is a fairly well-known mechanistic view of how $\mathrm{RH}$ cell expands, the environmental signals that trigger the cell elongation process remain currently unknown. Due to its important role in root physiology, it has been anticipated that $\mathrm{RH}$ would be highly susceptible to environmental stresses such as heat or moderate temperature increase, which trigger extensive DNA methylation, 
PRX62 and PRX69 regulate RH growth at low-temperature

transcriptomic and proteomic changes (Valdés-López et al. 2016; Quint et al. 2016; Hossain et al. 2017). Although RH development during cold acclimation remains largely unexplored, it has been observed that many $\mathrm{RH}$-related genes respond to cold in the whole plant or seedlings (Maruyama et al. 2004; Hannah, Heyer \& Hincha 2005; Barah et al. 2013). It is known that plants may perceive cold by a putative receptor at the cell membrane and initiate a signal to activate the cold-responsive genes and transcription factors for mediating stress tolerance (Thomashow 1999; Penfield 2008; Ding et al., 2019; Nurhasanah Ritonga and Chen, 2020; Leuendorf et al., 2020). Previously, we have shown that the plant long noncoding RNA (InCRNA) AUXIN REGULATED PROMOTER LOOP (APOLO) recognizes the locus encoding the $\mathrm{RH}(\mathrm{RH})$ master regulator RHD6 (Root Hair Defective 6) and controls RHD6 transcriptional activity leading to cold-enhanced $\mathrm{RH}$ elongation through the consequent activation of RSL4 (Moison et al. 2021). In addition, APOLO is able to bind and positively control the expression of several cell wall EXTENSIN (EXT) encoding genes, including EXT3, a key regulator for RH growth (Martinez-Pacheco et al. 2021). Unexpectedly, our previous results indicate that the lowtemperatures $\left(10^{\circ} \mathrm{C}\right)$ are able to trigger an exacerbated $\mathrm{RH}$ growth compared with cell expansion at room temperature (Moison et al. 2021; Martinez-Pacheco et al. 2021). To explore the molecular basis of this strong growth response, we conducted Genome Wide Association Studies (GWAS) on Arabidopsis thaliana natural accessions and identified the uncharacterized PEROXIDASE 62 (PRX62) as a key protein that regulates the conditional growth under a moderate low temperature stress. In addition, we also identified a second PRX, i.e. PRX69, as an important player in this developmental response. Both, PRX62 and PRX69 are key enzymes to trigger RH growth, likely by participating in a ROS-mediated mechanism of polar cell growth at low-temperatures. The expression of both PRX encoding genes could be under the regulation of RSL4, which has a direct binding to PRX69 promoter specific regions. Transcriptomic analyses revealed that upon $P R X 62$ and $P R X 69$ knockout, several other PRXs and cell wall EXTs encoding genes were differentially expressed, hinting at a compensatory mechanism.

\section{RESULTS AND DISCUSSION}

\section{PRX62 and PRX69 emerged as positive regulators of RH growth at low-temperatures.}

In order to identify the natural genetic components involved in $\mathrm{RH}$ growth under low-temperature conditions (at $10^{\circ} \mathrm{C}$ ), we analyzed natural $A$. thaliana accessions originated from contrasting environments (Europe, Asia, Africa and North America, Figure S1). We assessed RH growth for each seedling accession grown under $22^{\circ} \mathrm{C}$ for 5 days, and then transferred them to $10^{\circ} \mathrm{C}$ for 3 days. RH length was the phenotypic trait recorded for each accession, and compared to seedlings grown at $22^{\circ} \mathrm{C}$ for 8 days, taken as a control. We observed 15 -folds range of natural variation for average $\mathrm{RH}$ length $(148-2218 \mu \mathrm{m})$ in the accessions grown at $10^{\circ} \mathrm{C}$ (Figure S2A; Table S1) in contrast with a lower variability ( $\sim$-folds) and significantly shorter overall $\mathrm{RH}$ cells when seedlings were grown at $22^{\circ} \mathrm{C}$ 
PRX62 and PRX69 regulate $\mathrm{RH}$ growth at low-temperature

$(136-1034 \mu \mathrm{m})$. There is a strong correlation $\left(R^{2}=0.981\right)$ for $\mathrm{RH}$ length from accessions grown at $22^{\circ} \mathrm{C} \rightarrow 10^{\circ} \mathrm{C}$ compared to plants growth at $22^{\circ} \mathrm{C}$ (Figure $\mathbf{S 2 B}$ ), indicating that accessions respond in the same manner to a temperature decrease but varying in intensity. Only the most contrasting accession are shown as examples (Figure 1A). Thus, moderate low-temperature triggers $\mathrm{RH}$ polargrowth across Arabidopsis ecotypes by a yet unknown molecular mechanism. To identify candidate genes involved in $\mathrm{RH}$ growth response at moderate low-temperature, we performed a GWAS (GWAPP web tool, Seren et al, 2012) using as input data the RH length recorded only at $22^{\circ} \mathrm{C}$ or at $22^{\circ} \mathrm{C} \rightarrow 10^{\circ} \mathrm{C}$ for each accession (Table S1). When GWAS was performed measuring RH length obtained at $22^{\circ} \mathrm{C}$, no significant associations were identified (Figure 1B). On the other hand, after filtering SNPs for a $10 \%$ minor allele frequency in the $22^{\circ} \mathrm{C} \rightarrow 10^{\circ} \mathrm{C}$ RH length GWAS, a leader SNP m190905 (TAIR10 position 15847854) was significantly associated with RH length (LOD [for log of the odds] $=6.01, \mathrm{FDR}=0.06$ ) with RH length. This SNP is located in the intron of PEROXIDASE62 (PRX62, AT5G39580). Three additional SNPs located in $P R X 62$ exons, in high linkage disequilibrium with m190905 ( $\left.r^{2}>0.7, p<0.001\right)$, showed relatively high LOD score of association (m190904/15847644, $\mathrm{m} 190907 / 15848071, \mathrm{~m} 190909 / 15848704$, LOD 4.99-4.24, Figure 1C). These four SNPs formed seven haplotypes, with two major allele-opposite haplotypes (CTGT, n=79; TGAA, $n=18$ ), two haplotypes with very low frequency (CTGA, $n=5 ;$ TGGA, $n=5$ ) and three unique haplotypes (Figure S3A). Analysis of variance between the average trait values for all non-unique haplotypes showed that $\mathrm{RH}$ length varies among them, having the first and second most frequent haplotypes significantly different values for RH length (Figure S3B). In addition, PRX62 presents two splice variants, differing in the sequence length of the last exon. We then analyzed if these two $P R X 62$ isoforms can be equally detected and if low-temperature treatment induces a differential expression of any of them. According to Figure 1D, only the full-length transcript of PRX62 (AT5G39580.1) is detectable in the Col-0 that increased up to $2.54 \log _{2} \mathrm{FC}$ in roots under low-temperature (RNA-seq). This was further confirmed by RT-qPCR (Figure S4). Altogether, our results hinted at PRX62 as a potential key factor in the regulation of $\mathrm{RH}$ growth under low-temperature. Interestingly, according to publicly available datasets of whole seedlings (Schlaen et al. 2015), six PRX genes appeared as induced at $10^{\circ} \mathrm{C}$; notably PRX62 and PEROXIDASE69 (PRX69, AT5G64100) were predicted to be highly expressed in RHs (Table S2). PRX69 also has two predicted variants, the full length AT5G64100.1 and a shorter one AT5G64100.2. By RNA-seq we also confirmed that only the full-length variant of PRX69 is the most expressed one with an small upregulation (by $0.21 \log _{2} \mathrm{FC}$ ) by low temperature although with similar overall transcriptional levels to PRX62 (Figure 2D). This was also confirmed by RT-qPCR (Figure S4). Therefore, we decided to characterize in depth both PRXs, PRX62 and PRX69 and their roles in RH growth at $10^{\circ} \mathrm{C}$.

In agreement with GWAS results, low-temperature-mediated growth requires peroxidase activity since the treatment with salicylhydroxamic acid (SHAM), a peroxidase inhibitor (Kim et al. 2012; Kwon et al. 2015) at inhibitory concentration $50 \%\left(\mathrm{IC}_{50}=65 \mu \mathrm{M}\right)$ at $22^{\circ} \mathrm{C}$ was able to repress up to $90 \%$ of this 
PRX62 and PRX69 regulate $\mathrm{RH}$ growth at low-temperature

115

116

117

118

119

120

121

122

123

124

125

126

127

128

129

130

131

132

133

134

135

136

137

138

139

140

141

142

143

144

145

146

147

148

149

150

151

152

growth response at low temperature (Figure 2A-B). Accordingly, peroxidase activity in whole roots was significantly lower under the SHAM treatments at both temperatures (Figure 2C). We then tested if $P R X 62$ and $P R X 69$ expression levels were different between contrasting accessions based on the $\mathrm{RH}$ phenotype at $10^{\circ} \mathrm{C}$ (Figure 2D; Figure S4). Transcript levels of $P R X 62$ (after 3 days at $10^{\circ} \mathrm{C}$ ) were positively correlated with the $\mathrm{RH}$ length of the given accession, i.e. that the higher the expression of PRX62 at $10^{\circ} \mathrm{C}$, the longer the RHs. This implies that high levels of PRX62 in Wc-1 and very low levels in $\mathrm{Bu}-2$ accessions might be linked to the differential $\mathrm{RH}$ phenotype detected at low-temperature and suggests that the causal variation for $\mathrm{RH}$ length is dependent on PRX62 higher expression (Figure 2D; Figure S4). On the contrary, PRX69 transcript levels are higher at $10^{\circ} \mathrm{C}$, but they did not show any significant variation across accessions. Altogether, these results suggest that upregulation of $P R X 62$ transcript levels together with high levels of PRX69 play an important role in $\mathrm{RH}$ growth at lowtemperature.

\section{PRX62 and PRX69 regulate RH growth under low-temperature.}

The in silico analysis of PRX62 and PRX69 expression using Tissue Specific Root eFP (http://bar.utoronto.ca/eplant/) showed that both PRX encoding genes were confined to differentiated $\mathrm{RH}$ cells with expression in the elongation phase at similar levels than the $\mathrm{RH}$ marker EXPANSIN 7 (Figure 3A). Accordingly, the corresponding reporter lines of PRX62 ${ }_{\text {pro }} G F P$ as well as $P R X 69_{\text {pro }} G F P$ showed high levels of signal in $\mathrm{RH}$ cells when grown at $10^{\circ} \mathrm{C}$ while lower expression was detected at $22^{\circ} \mathrm{C}$ (Figure 3B). When PRX62 and PRX69 tagged constructs (35S pro $P R X 62-T a g R F P$ and $\left.35 S_{\text {pro }} P R X 69-T a g R F P\right)$ are transiently coexpressed in Nicotiana benthamiana leaves with a plasma membrane marker, both PRXs showed an apoplastic localization (Figure S5). Overall, these results confirm that PRX62 and PRX69 are both cold-responsive specific RH class III PRXs that are secreted to the apoplastic space in the cell wall. In order to test if the absence of PRX62 and PRX69 is able to modify growth response at $10^{\circ} \mathrm{C}$, we assessed two T-DNA mutants for PRX62 in the Col-0 background (prx62-1 and prx62-2), being a knock-out (prx62-1) and a knock-down (prx62-2) allele, respectively (Jemmat et al. 2020). In addition, we also characterized two previously reported T-DNA mutants for PRX69 (prx69-1 and prx69-2) (Jemmat et al. 2020). By RNA-seq, we confirm they were absence of transcripts for both PRX62 and PRX69 in these mutants (Figure S6A). Only in prx69-1 when grown at $10^{\circ} \mathrm{C}$ we found a truncated transcript of PRX69 (Figure S6B). The RH phenotype in both prx62 and prx69 single mutants were similar to Col-0 at $22^{\circ} \mathrm{C}$ and at $10^{\circ} \mathrm{C}$ (Figure $3 \mathrm{C}$ ) while the double mutant prx62-1 prx69-1 showed significantly shorter RHs than Col-0 and any of the single mutants prx62 and prx69 at $10^{\circ} \mathrm{C}$. The double prx62-1 prx69-1 mutant showed no detectable transcript levels of both PRXs (Figure S6C). The overall peroxidase activity was also partially impaired in single mutants prx621 and prx69-1 and double mutant prx62-1 prx69-1 at both growth temperatures, $22^{\circ} \mathrm{C}$ and $10^{\circ} \mathrm{C}$ (Figure 3D). We then tested RH growth complementation of the prx62-1 prx69-1 double mutant by

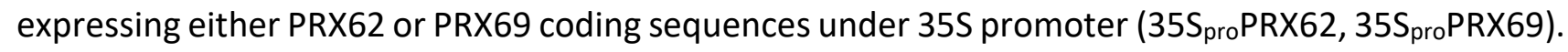
The $\mathrm{RH}$ growth was restored comparable to Col-0 levels at $10^{\circ} \mathrm{C}$ only for PRX62 but not for PRX69 
PRX62 and PRX69 regulate RH growth at low-temperature

(Figure S7). This suggests that high levels of $P R X 62$ but not of $P R X 69$ are able to compensate the absence of both PRXs in prx62 prx69 double mutant. To determine whether higher expression of the $P R X 62$ and $P R X 69$-encoding genes are sufficient to trigger changes in $\mathrm{RH}$ cell length, we generated a constitutive $35 S_{\text {pro }} P R X 62$ overexpression lines in the Col-0 background that expressed up to 13-52 folds of transcripts levels of PRX62 as well as the corresponding 35S pro $P R X 69$ overexpression lines with 9-11 folds (Figure S6C). As expected, PRX62 overexpression resulted in significantly longer RH cells than their respective Col-0 while PRX69 overexpression failed to trigger enhanced growth (Figure 3E). This may indicate that PRX62 and PRX69 do not have equal functions in RH growth although both PRXs are required for this enhanced low-temperature growth process. Taken together, these results indicate that the amount of PRX62 and PRX69 proteins linked to their peroxidase activities control $\mathrm{RH}$ growth at $10^{\circ} \mathrm{C}$.

\section{The absence of PRX62 and PRX69 induced a deregulation of several PRXs and cell wall EXTs at low-} temperature.

To better understand the transcriptional changes produced at low temperature in a PRX62- and PRX69-dependent manner, we performed an RNA-seq analysis comparing Col-0 and the double prx62-1 prx69-1 mutant at $10^{\circ} \mathrm{C}$ or $22^{\circ} \mathrm{C}$. We found a central core of 1544 differentially expressed genes (DEG) at low-temperature grouped into 10 clusters that were misregulated in the double prx62-1 prx69-1 mutant compared to Col-0 (Figure 4A). 1022 genes were upregulated (clusters 1-6) and 522 were downregulated (clusters 7-10) in Col-0 compared to the double prx62 prx69 mutant. We focused on the largest clusters 1, 2 and cluster 4 (comprised by 873 genes) where the genes upregulated in Col-0 were deregulated in double prx62 prx69 mutant in response to cold. In these gene clusters, overrepresented GO terms were linked to plant cell walls, extracellular domains, and secretory pathway (Figure 4B). We identified several over-represented PRXs (15 genes) and EXTsrelated proteins ( 7 encoding genes) suggesting a global change in ROS-homeostasis and EXTs cell wall remodeling in the double prx62-1 prx69-1 mutant at low-temperature (Figure 4A-B). Some of these genes (e.g. EXT6 and PRP1) showed a gene dose-dependent expression at transcript level linked to the $\mathrm{RH}$ growth phenotype at $10^{\circ} \mathrm{C}$ (Figure $4 \mathrm{C}$ ). This indicated that low-temperature induces global gene expression changes linked to the cell wall remodeling and ROS-homeostasis that positively enhance RH growth. The analysis highlights that the absence of PRX62 and PRX69 proteins triggers major changes in the transcriptional program of other PRXs and EXTs genes at low-temperature. This implies the existence of a feedback regulatory loop from the apoplast-cell wall compartments that triggers major changes at the transcriptional level of cell wall proteins and apoplastic PRXs.

\section{PRX62 and PRX69 affect ROS-homeostasis in RH cells under low-temperature.}

To get a deeper insight into PRX62 and PRX69 functions in growing RHs at moderate lowtemperature, we explored the effect of these PRXs on Reactive Oxygen Species (ROS)-homeostasis. Overall PRX functions are linked to ROS, which are one of the key factors regulating polar growth in 
PRX62 and PRX69 regulate RH growth at low-temperature

RHs (Mangano et al. 2017; Mangano et al. 2018; Marzol et al. 2018). Then, we measured total cytoplasmic ROS (cytROS) using the cell-permeable fluorogenic probe $2^{\prime}, 7^{\prime}$-dichlorodihydrofluorescein diacetate ( $\mathrm{H}_{2} \mathrm{DCF}-\mathrm{DA}$ ) and apoplastic ROS (apoROS) levels with cell-impermeable Amplex ${ }^{\mathrm{TM}}$ UltraRed Reagent in $\mathrm{RH}$ tips at $22^{\circ} \mathrm{C}$ and $10^{\circ} \mathrm{C}$ (Figure 5A-B). The double mutant prx62-1 prx69-1 showed higher levels of ${ }_{\text {cyt }} \mathrm{ROS}$ at $10^{\circ} \mathrm{C}$ in actively growing $\mathrm{RH}$ tips compared to Col-0 (Figure $5 \mathrm{~A}$ ) while this enhance in ROS level is less evident at $22^{\circ} \mathrm{C}$ between the double mutant prx62-1 prx69-1 and Col-0. In agreement, in the plants overexpressing PRX62 or PRX69, cyt ROS were reduced at both $22^{\circ} \mathrm{C}$ and $10^{\circ} \mathrm{C}$. On the other hand, the apoROS in the RH tip were enhanced in Col- 0 at $10^{\circ} \mathrm{C}$ compared to the levels at $22^{\circ} \mathrm{C}$ while they were lower in the double mutant prx62-1 prx69-1 at both temperatures. In the lines overexpressing PRX62 or PRX69, cytROS were enhanced at both $22^{\circ} \mathrm{C}$ and $10^{\circ} \mathrm{C}$ (Figure 5B). The increased level of apoROS in Col-0 under low-temperature is in agreement with a two-fold increase in the transcript levels for NOXC (RBOHC), a key enzyme-encoding gene for ROS production (Figure S8). Collectively, these results suggest that ROS-homeostasis is drastically modified in an antagonistic manner by the absence or overexpression of these two PRXs when $\mathrm{RH}$ grow at $10^{\circ} \mathrm{C}$, affecting RH cell elongation.

\section{Low-temperature enhances EXTENSIN cell wall insolubility in RH cells.}

EXT-crosslinking can provide architectural stabilization for normal wall reinforcement during cell elongation (Srivastava, 2002; Cannon et al., 2008; Bashline et al., 2014; Bidhendi and Geitmann, 2016; Yaqoob et al., 2020). Since changes in ROS-homeostasis could lead to abnormal cell wall secretion and structure, we wondered whether PRX62 and PRX69 might participate in the cell wall glycoprotein EXTs crosslinking during $\mathrm{RH}$ growth at low-temperature. Then, we tested if low-temperature could induce a change in the targeting of EXTs secreted and insolubilized in the wall by the activity of these two PRXs. To this end, we used an EXT-reporter carrying a tdTomato tag (SS-TOM-Long-EXT) that is resistant to acidic $\mathrm{pH}$, a condition usually found in the cell wall- apoplast compartments, and a secreted tdTomato tag (SS-TOM) was used as a control (Marzol et al. 2021). The signal coming from the cell surface in the apical zones of RHs cells under plasmolysis conditions were determined for SSTOM-Long-EXT and SS-TOM constructs at $22^{\circ} \mathrm{C} / 10^{\circ} \mathrm{C}$ temperatures and SHAM-treated/non-treated roots (Figure 5C). Plasmolysis allowed us to retract the plasma membrane and define the EXT-signal coming specifically from the cell walls. Interestingly, of cell wall stabilization/insolubility of SS-TOMLong-EXT in the RH tip was drastically augmented at $10^{\circ} \mathrm{C}$ compared to $22^{\circ} \mathrm{C}$. Furthermore, the signal increment at $10^{\circ} \mathrm{C}$ was completely abolished when roots were treated with the peroxidase inhibitor SHAM (Figure 5C). Thus, the SS-TOM-Long-EXT reporter tested in the apical zone of the RHs is modified by low-temperature and by the peroxidase activity, at least partially possibly exerted by PRX62 and PRX69 in the apoplast. This result suggests that changes in ROS-homeostasis produced by altered levels of these PRXs in the apoplast might affect the secretion, targeting and, possibly the crosslinking of cell wall components including EXTs, affecting RH cell elongation (Figure 6). 
PRX62 and PRX69 regulate RH growth at low-temperature

\section{RSL4 transcription factor binds to the PRX69 promoter E -boxes.}

It was previously shown that RSL4 controls RH growth at low-nutrient conditions (Mangano et al. 2017; Mangano et al. 2018) and at low-temperature (Moison et al. 2021). Moreover, it was also shown that RSL4 directly controls the expression of $P R X 01, P R X 44$ and $P R X 73$, three PRX-encoding genes important for $\mathrm{RH}$ growth at low-nutrient condition at room temperature (Mangano et al. 2017; Marzol et al. 2021). Thus, we wondered whether RSL4 was able to regulate directly the expression of $P R X 62$ and/or PRX69. To this end, we first measured $P R X 62$ and PRX69 transcript levels in $r s / 4$ and $r s / 2$ rs/4 mutants, which is impaired in RH growth enhancement, and in the RSL4 overexpressing line (35S pro $_{\text {RSL4) }}$ ) that develops extra-long RHs regardless the media and temperature conditions (Moison et al. 2021). PRX62 expression might be positively regulated (indirectly or directly) by RSL2 but not by RSL4 based on the expression profiles in the double mutant $r s / 2$ rs/4 versus $r s / 4$ and $35 S_{\text {proRSL4. }}$ PRX62 expression enhancement at low temperature is only repressed when $r s / 2$ mutation is present (Figure S9A). On the other hand, an increase of 4.3-folds of PRX69 transcripts were detected when compared $35 \mathrm{~S}_{\text {pro }} \mathrm{RSL} 4 / \mathrm{rs} / 4$ (Figure S9A). To test if any of these genes was directly regulated by RSL4, we tested by ChIP-qPCR the binding of RSL4-GFP in the predicted sites (E-boxes) of PRX62 and PRX69 promoters using the positive control of EXPANSIN7 and $L R X 1$, two previously reported direct targets of RSL4 (Hwang et al. 2017) and PP2A as a negative control (Figure S9B). We detected a mild binding of RSL4 protein to one of the predicted E-box sequences in the promoter region PRX69. Altogether, our results indicate that RSL4 positively controls the expression of PRX69 in a direct manner while the regulation of $P R X 62$ might be related to RSL2. Further research will be required to determine if auxin-ARFs or yet unknown TFs independent of auxin pathway (e.g. RHD6) regulates the expression of RSL4 under this low-temperature condition. Overall, this work uncovers the key roles of two previously poorly described PRXs, PRX62 and PRX69, in the regulation of low temperature ROS homeostasis and EXT insolubilization in the cell walls that determines an enhanced RH growth. It is hypothesized that these two PRXs might modulate the cell wall EXT-mediated assembly during this fast cell elongation process (Figure 6).

\section{CONCLUSIONS}

Despite the putative high overall genetic redundant functions of apoplastic Class-III PRXs, in the last years several individual PRXs were characterized to be involved in the oxidative polymerization of monolignols in the apoplast of the lignifying cells in xylem (e.g. PRX17; Cossio et al 2017), in the root endodermis (e.g. PRX64; Lee et al. 2013) or in petal detachment (Lee et al 2018). Moreover, PRXs are also able to polymerize other components of the plant cell wall, including suberin, pectins and EXTs (Schnabelrauch et al., 1996; Bernards et al., 1999; Jackson et al., 2001; Francoz et al. 2019). While several candidates of PRXs have been described in divers plants to be associated specifically to EXTs crosslinking (EXT-PRXs) by in vitro studies (LEP1, GVEP1 and FBP1) or inmunolocalization evidences 
PRX62 and PRX69 regulate RH growth at low-temperature

linked them to transient activity measurements (PRX08 and PRX34) (Schnabelrauch et al., 1996; Wojtaszek et al., 1997; Jackson et al., 2001; Price et al., 2003; Pereira et al. 2011; Dong et al., 2015; Jacobowitz et al. 2019), their role in vivo remains largely unexplored. Previously it was demonstrated that three PRXs (PRX01, PRX44 and PRX73) directly contribute to ROS-homeostasis and RH growth at room temperature $\left(22^{\circ} \mathrm{C}\right)$ under low-nutrient condition (Mangano et al. 2017; Marzol et al. 2021). By using a GWAS-RNAseq approach, we identified here two previously poorly characterized apoplastic peroxidases, PRX62 and PRX69 (Jemmat et al. 2020), as positive regulators of RH growth at lowtemperature $\left(10^{\circ} \mathrm{C}\right)$. One of the key results of this work is that PRX62 was found using GWAS while PRX69 was identify on the transcriptomic profile. This point out to a different evolutionary history for both proteins. PRX62 has evolved to give a dose response according to the allele encoded in the genome, while PRX69 have a constitutive response at low temperature. These features of PRX62 and PRX69 can be useful in crop improvement, to select varieties with differential responses; better adapted to the environment they are exposed. The evidences shown here indicate that PRX62 and PRX69 are involved in the ROS-homeostasis linked to the association of EXTs to the cell wall during $\mathrm{RH}$ cell elongation at low-temperature (Figure 6). We speculate that cell wall insolubilization/association of EXTs triggered by low-temperature might not only involve Tyr-covalent crosslinks mediated by these two PRXs identified here but also by EXT hydrophobic associations nondependent on Tyr as suggested before for Leucine-Rich Extensins 1 (LRX1; Ringli 2010). Further analyses might shed light on these complex processes.

Previously, our group as well as others have documented that changes in any of the several posttranslational modifications in EXTs and related-EXTs like LRXs (e.g. proline hydroxylation, $O$ glycosylation, and Tyr-crosslinking), all affected RH growth (Baumberge et al. 2001, 2003; Velasquez et al. 2011; Velasquez et al. 2015; Marzol 2018, 2021) as well as pollen tube growth (Fabrice et al. 2017; Sede et al. 2017; Wang et al. 2017). In addition, auxin-dependent ROS-homeostasis controlled by three apoplastic PRXs (e.g. PRX01, PRX44, PRX73) and plasmamembrane RBOHC protein (also known as RHD2, for RH Defective 2) was shown to be determinant for a proper RH growth under low nutrient condition (Mangano et al 2017; Marzol et al. 2021) or under low temperature (MartinezPacheco et al. 2021). Collectively, these evidences highlight the predominant role of ROShomeostasis partially regulated by specific PRXs as a key component in polar RH elongation. The molecular mechanism by which low-temperature-associated nutrient availability in the media (Moison et al. 2021) triggers the expression of these two specific PRXs remains unclear, although RSL4 could play a central role in the regulation of this mechanism. Previously, we have shown that the IncRNA APOLO binds to the locus of RHD6 and controls RHD6 transcriptional activity leading to cold-enhanced RH elongation through the consequent activation of RSL4 (Moison et al. 2021) and of several cell wall EXTENSIN (EXT) encoding genes (Martinez-Pacheco et al. 2021). Unexpectedly, our previous results indicate that the low-temperatures $\left(10^{\circ} \mathrm{C}\right)$ are able to trigger an exacerbated $\mathrm{RH}$ growth compared with cell expansion at room temperature (Moison et al. 2021; Martinez-Pacheco 
bioRxiv preprint doi: https://doi.org/10.1101/2021.08.20.456256; this version posted August 20,2021. The copyright holder for this preprint (which was not certified by peer review) is the author/funder, who has granted bioRxiv a license to display the preprint in perpetuity. It is made available under aCC-BY-NC-ND 4.0 International license.

PRX62 and PRX69 regulate $\mathrm{RH}$ growth at low-temperature

305 et al. 2021). Moreover, further research will be needed to uncover the nutritional signal perceived at 306 the RH cell surface to trigger PRX62 and PRX69 low temperature mediated growth response. The 307 expression levels of PRX62 and PRX69 orthologs in other Brassicaceae could be used as biomarkers 308 for crop improvement in the selection of genotypes with longer RHs at moderate low-temperatures 309 in order to boost nutrients uptake in deficient soils. 
PRX62 and PRX69 regulate RH growth at low-temperature

EXPERIMENTAL PROCEDURES

311

312

313

314

315

316

317

318

319

320

321

322

323

324

325

326

327

328

329

330

331

332

333

334

335

336

337

338

339

340

341

342

343

344

345

346

347
Plant genotyping and growth conditions. Arabidopsis thaliana Columbia-0 (Col-0) was used as the wild type $(\mathrm{Wt})$ genotype in all experiments unless stated otherwise. Seedlings were surface sterilized and stratified in darkness at $4^{\circ} \mathrm{C}$ for 3 days before been germinated on $1 / 2$ strength MS agar plates supplemented with MES (Duchefa, Netherlands), in a plant growth chamber in continuous light (120 $\mu \mathrm{mol} . \mathrm{sec}^{-1} \cdot \mathrm{m}^{-2}$ ). Plants were transferred to soil for growth under the same conditions as previously described at $22^{\circ} \mathrm{C}$. Mutants and transgenic lines developed and used in this study are listed in Table S3. For identification of T-DNA knockout lines, genomic DNA was extracted from rosette leaves. Confirmation by PCR of a single and multiple T-DNA insertions in the genes were performed using an insertion-specific LBb1 or LBb1.3 (for SAIL or SALK lines, respectively) or 8474 (for GABI line) primer in addition to one gene-specific primer. In this way, we isolated homozygous for all the genes. Arabidopsis T-DNA insertions lines (prx62-1 [GK_287E07], prx62-2 [SALK_151762], prx69-1 [SAIL_691_G12], prx69-2 [SALK_137991]) were obtained from the European Arabidopsis Stock Centre (http://arabidopsis.info/). Using standard procedures homozygous mutant plants were identified by PCR genotyping with the gene-specific primers listed in Table S4. T-DNA insertion sites were confirmed by sequencing using the same primers. Plants were routinely grown in Jiffy peat pellets (continuous light, $120 \mu \mathrm{mol}$ photons $/ \mathrm{m} / \mathrm{s}, 22^{\circ} \mathrm{C}, 67 \%$ relative humidity). For in vitro experiments, seeds were surface-sterilized and sown in Petri dishes on agar-solidified half-MS medium without sucrose, and grown in a culture room with continuous light $\left(120 \mu \mathrm{mol}\right.$ photons $\left./ \mathrm{m} / \mathrm{s}, 22^{\circ} \mathrm{C}\right)$.

Root hair phenotype. Seeds were surface sterilized and stratified in darkness for 3 days at $4{ }^{\circ} \mathrm{C}$. Then grew on $1 / 2$ strength MS agar plates supplemented with MES (Duchefa, Netherlands), in a plant growth chamber at $22^{\circ} \mathrm{C}$ in continuous light $\left(120 \mu \mathrm{mol} . \mathrm{sec}^{-1} \cdot \mathrm{m}^{-2}\right)$ for 5 days at $22^{\circ} \mathrm{C}+3$ days at $10^{\circ} \mathrm{C}$ or for 8 days at $22^{\circ} \mathrm{C}$ as control. For quantitative analysis of root hair cell length phenotypes, 10 fully elongated $\mathrm{RHs}$ from the elongation root zone were measured from 15-20 roots. Measurements were made after 8 days. Images were captured with an Olympus SZX7 Zoom Stereo Microscope (Olympus, Japan) equipped with a Q-Colors digital camera and QCapture Pro 7 software (Olympus, Japan) and digitally processed with ImageJ software. $\mathrm{RH}$ length values were reported as the mean of three replicates \pm SD using the GraphPad Prism 8.0.1 (USA) statistical analysis software.

GWAS analysis and haplotype analysis. To perform Genome Wide Association Analysis (GWAS), 106 Arabidopsis thaliana natural accessions were phenotyped for $\mathrm{RH}$ length in a shift- temperature experiment as described above (Table S1). The population was previously genotyped using 214,051 Single Nucleotide Polymorphisms (SNPs) and this information is publicly available (Horton et al., 2012). These set of phenotypes and genotypes were used to performed GWAS on the GWAPP web application from the GWA-Portal (Seren et al, 2012, https:/gwas.gmi.oeaw.ac.at/\#/home, Experiment code: 3b316208-0b5d-11e7-b6b1-005056990049) applying the accelerated mixed model, 
PRX62 and PRX69 regulate RH growth at low-temperature

AMM (Kang et al., 2008; Zhang et al., 2010, Kang et al. 2010). A total of 139,425 SNPs with minor allele frequency (MAF) $\geq 10 \%$ were retained for further analysis. P-values of association were logtransformed to LOD values ( $-\log _{10}(p$-value)) and corrected for multiple comparisons using FDR procedure (Benjamini and Hochberg, 1995). The threshold for significant associations was set to $p$ value $\leq 1 / \mathrm{N}$ (where $\mathrm{N}$ is the number of SNPs=139,425) as described previously (Wen et al. 2014). Manhattan plots were obtained using the qqman package (Turner, 2017) in R (2013), filtering out the SNPs with $p$-value $>0.4$, to minimize overrepresentation of non-significant SNPs. Linkage disequilibrium, i.e. the degree to which an allele of one SNP co-occurs with an allele of another SNP within a population, was calculated as square coefficient of correlation $\left(r^{2}\right)$ and visualized using the LDheatmap package (Shin et al., 20006) in R. Three additional SNPs in the PRX62 genomic region (m190904, m190907, m190909) in high linkage disequilibrium $\left(r^{2}>0.7, p<0.001\right)$ with the lead SNP m190905 were used in the haplotype analysis. Mean trait values for each non-unique haplotype were analyzed using ANOVA followed by Tukey test implemented in Infostat (Di Rienzo et al. 2011).

Peroxidase activity. Soluble proteins were extracted from roots grown on vertical plates for 10 days at $22^{\circ} \mathrm{C}$ or $10^{\circ} \mathrm{C}$ by grinding in $20 \mathrm{mM}$ HEPES, pH 7.0, containing $1 \mathrm{mM} \mathrm{EGTA}, 10 \mathrm{mM}$ ascorbic acid, and PVP PolyclarAT (100mg/g fresh material)(Sigma, Buchs, Switzerland). The extract was centrifuged twice for $10 \mathrm{~min}$ at 10,000 g. Each extract was assayed for protein levels with the Bio-Rad protein assay (Bio-Rad, USA). Enzyme activity (expressed in nkatal/mg protein) was determined at $25^{\circ} \mathrm{C}$ by following the oxidation of $8 \mathrm{mM}$ guaiacol (Fluka ${ }^{\mathrm{TM}}$, Honeywell International,USA) at $470 \mathrm{~nm}$ in the presence of $2 \mathrm{mM} \mathrm{H}_{2} \mathrm{O}_{2}$ (Carlo Erba, Italy) in a phosphate buffer ( $200 \mathrm{mM}, \mathrm{pH6.0}$ ). Values are the mean of three replicates \pm SD. P-value of one-way ANOVA, $\left({ }^{* *}\right) \mathrm{P}<0.01$.

Gene transcript analysis by Reverse Transcription followed by quantitative PCR (RT-qPCR). Total RNA was prepared from 10 days old in vitro-grown plantlets using the TRI ${ }^{\mathrm{TM}}$ Reagent Solution (SigmaAldrich). After quantification by spectrophotometry and verification by electrophoresis, RNA was treated with the RQ1 RNase-free DNase I (Promega). One microgram of total RNA was reverse transcribed using an oligo(dT) 15 and the MMLV-RT (Promega) according to the manufacturer's instructions. cDNA was diluted 20-fold before PCR. RT-qPCR were performed on a QuantStudio 6 Flex Real-Time PCR System (Thermo Fisher) using $5 \mu \mathrm{L}$ Power SYBR Green PCR Mix (Applied Biosystems), $2 \mu \mathrm{L}$ of $\mathrm{cDNA}$, and $0.3 \mu \mathrm{M}$ of each primer in a total volume of $10 \mu \mathrm{L}$ per reaction. Primers used are listed in Table S4. ACT2 (AT3G18780) and UBQ1 (AT3G52590) genes were used as references for normalization of gene expression levels. The cycling conditions were $95^{\circ} \mathrm{C}$ for $10 \mathrm{~min}$., 40 cycles of $95^{\circ} \mathrm{C}$ for $15 \mathrm{sec}$., $60^{\circ} \mathrm{C}$ for $1 \mathrm{~min}$. and finally a melting curve from $60^{\circ} \mathrm{C}$ to $95^{\circ} \mathrm{C}\left(0.05^{\circ} / \mathrm{sec}\right)$. Under these conditions primers efficiency was found to be between 97.0 and $99.7 \%$. No amplification occurred in the no-template controls. Data were analyzed using the Standard curve method (Pfaffl, 2001) and Qiagen RESTC 2009 software (Pfaffl et al., 2002). Three independent experiments (and two technical replicates per experiment) were performed. 
PRX62 and PRX69 regulate RH growth at low-temperature

386

387

388

389

390

391

392

393

394

395

396

397

398

399

400

401

402

403

404

405

406

407

408

409

410

411

412

413

414

415

416

417

418

419

420

421

422

PRXs-tagged reporter lines. For the PRX62proGFP and PRX69proGFP reporter lines, a $1.5 \mathrm{~kb}$ genomic region upstream of the ATG start codon of each PRX62 (AT5G39580) and PRX69 (AT5G64100) genes was selected using ThaleMine (https://bar.utoronto.ca/thalemine/begin.do) synthetized and cloned into the pUC57 vector by GenScript Biotech(USA). Through Gateway cloning Technology (Invitrogen) the $1.5 \mathrm{~kb}$ upstream regions were recombined first in PDONR ${ }^{\mathrm{TM}} 207$ vector and subcloned into pMDC111 destination vector (Invitrogen; (Karimi et al., 2002)) for PRX69 promoter region and into pGWB4 vector (Invitrogen; (Nakagawa et al 2007)) for PRX62 promoter region. These constructs were checked by restriction analysis. Both vectors contain a cassette with a C-terminal GFP tag. For the PRXs-TagRFP lines, the PRX62 and PRX69 coding sequence was amplified by PCR from $A$. thaliana 10day old plantlets cDNAs using specific primers (Table S4). The PCR product was digested with HindIII and BamHI (PRX62) or with EcoRI and Smal (PRX69), and cloned into Gateway ${ }^{\circledR}$ TagRFP-AS-N entry clone (Evrogen). The PRX62-TagRFP fusion was subcloned (Gateway Technology, Invitrogen) into the pB7WG2 destination vector (Karimi et al., 2002) containing a $35 \mathrm{~S}$ promoter. This construct was checked by restriction analysis and sequencing. The same procedure was use to generate 35S-PRX69TagRFP construct. All the constructs were used to transform $A$. thaliana plants and obtain homozygous stable fluorescent lines.

Confocal Microscopy: Confocal laser scanning microscopy for the lines PRX62pro-GFP and PRX69proGFP, was performed using Zeiss LSM5 Pascal (Zeiss, Germany) (Excitation: $488 \mathrm{~nm}$ argon laser; Emission: $490-525 \mathrm{~nm}, 10 \mathrm{X}$ objective N/A 0.30 or 40X water-immersion objective, N/A 1.2, according to experiment purpose). $Z$ stacks were done with an optical slice of $1 \mu \mathrm{m}$, and fluorescence intensity was measured at the RH tip. For the lines SS-TOMATO and SS-TOMATO-EXT LONG, roots were plasmolyzed with a mannitol $8 \%$ solution and the scanning was performed using Zeiss LSM5 Pascal (Zeiss, Germany)( Excitation: $543 \mathrm{~nm}$ argon laser; Emission: 560-600 nm, 63X water-immersion objective N/A 1.2) Three replicates for each of ten roots and between 10 to 15 hairs per root were observed. GFP signal and tdTOMATO cell wall signal at RH tip were quantified using the ImageJ software. Fluorescence $A U$ were reported as the mean of three replicates \pm SD using the GraphPad Prism 8.0.1 (USA) statistical analysis software.

Apoplastic and Cytoplasmic ROS measurement in RH Tip: To measure ROS levels in root hairs cells, 8 days-old Arabidopsis seedlings grown at $22^{\circ} \mathrm{C}$ (control) and $10^{\circ} \mathrm{C}$ in continuous light were used. For cytoplasmic ROS, the seedlings were incubated in darkness for 10 min with $50 \mu \mathrm{M} \mathrm{H2DCF-DA}$ (Thermo Fisher) at room temperature then washed with liquid 0.5X MS media (Duchefa, Netherlands) and observed with Zeiss Imager A2 Epifluorescence Microscope(Zeiss, Germany) (40X objective, N/A 1.2, exposure time $25 \mathrm{~ms}$ ). Images were analyzed using ImageJ software. To measure ROS levels, a circular region of interest was chosen in the zone of the root hair tip cytoplasm. Approximately, 20 healthy and alive root hairs of ten plants per treatment were analyzed. To measure apoplastic ROS, the 
PRX62 and PRX69 regulate $\mathrm{RH}$ growth at low-temperature

423

424

425

426

427

428

429

430

431

432

433

434

435

436

437

438

439

440

441

442

443

444

445

446

447

448

449

450

451

452

453

454

455

456

457

458

459

460

seedlings were incubated with $50 \mu \mathrm{M}$ Amplex ${ }^{\mathrm{TM}}$ UltraRed Reagent (AUR) (Molecular Probes, Invitrogen) for $15 \mathrm{~min}$ in darkness and rinsed with liquid 0.5X MS media (Duchefa, Netherlands). Root hairs were imaged with a Zeiss LSM5 Pascal (Zeiss, Germany)) laser scanning confocal microscope (Excitation: $543 \mathrm{~nm}$ argon laser; Emission: 560-610 nm, 40X water-immersion objective, N/A 1.2). The intensity of fluorescence was quantified on digital images using ImageJ software. Quantification of the AUR probing fluorescence signal was restricted to apoplastic spaces at the root hair tip. At least 10-15 hairs per plant and ten plants per treatment with three replicates were analyzed. Fluorescence $\mathrm{AU}$ were reported as the mean of three replicates \pm SD using the GraphPad Prism 8.0.1 (USA) statistical analysis software.

In silico analysis. The in silico analysis of $P R X 62$ and $P R X 69$ expression in the roots were performed using ePlant browser of Araport, Tissue Specific Root eFP (http://bar.utoronto.ca/eplant/) (Waese et al. 2017). EXPANSIN7 (EXP7) as a RH specific gene was included for comparison.

RNA-seq Analyses. This section is adapted from the 3D RNA-seq package output "Results" (Guo et al., 2020; Calixto et al., 2018) as this was the selected tool to analyze differential expression in our datasets. For the RNA-seq datasets we analyzed 2 datasets, one with 16 factor groups (Col.X10, Col.X22, Bu.X10, Bu.X22, Sf.X10, Sf.X22, Te.X10, Te.X22, Wc.X10, Wc.X22, P62.X10, P62.X22, P69.X10, P69.X22, P6269.X10, P6269.X22) each with 2 biological replicates (32 samples in total). Quantification of transcripts using salmon quant (Patro et al., 2017) from Galaxy.org or salmon-1.5.1_linux_x86_64 version in a personal computer. The index of the transcriptome was built using The Arabidopsis Thaliana Reference Transcript Dataset 2 (AtRTD2, Zhang R. et al., 2016) obtained from https://ics.hutton.ac.uk/atRTD/. For the data pre-processing, read counts and transcript per million reads (TPMs) were generated using tximport $\mathrm{R}$ package version 1.10 .0 and lengthScaledTPM method (Soneson et al., 2016) with inputs of transcript quantifications from tool salmon (Patro et al., 2017). Low expressed transcripts and genes were filtered based on analyzing the data mean-variance trend. The expected decreasing trend between data mean and variance was observed when expressed transcripts were determined as which had $\geq 1$ of the 32 samples with count per million reads (CPM) $\geq 1$, which provided an optimal filter of low expression. A gene was expressed if any of its transcripts with the above criteria was expressed. The TMM method was used to normalize the gene and transcript read counts to $\log _{2}$-CPM (Bullard et al., 2010). The principal component analysis (PCA) plot showed the RNA-seq data did not have distinct batch effects. For the DE, DAS and DTU analysis, the voom pipeline of limma R package was used for 3D expression comparison (Ritchie et al., 2015; Law et al., 2014). To compare the expression changes between conditions of experimental design, the contrast groups were initially set as Col.X10-Col.X22, Bu.X10-Bu.X22, Sf.X10-Sf.X22, Te.X10-Te.X22, Wc.X10-Wc.X22， P62.X10-P62.X22， P69.X10-P69.X22， P6269.X10-P6269.X22. For DE genes/transcripts, the $\log _{2}$ fold change $\left(L_{2} F C\right)$ of gene/transcript abundance were calculated based on contrast groups and significance of expression changes were determined using t-test. P-values of 
PRX62 and PRX69 regulate RH growth at low-temperature

461

462

463

464

465

466

467

468

469

470

471

472

473

474

475

476

477

478

479

480

481

482

483

484

485

486

487

488

489

490

491

492

493

494

495

496

497

498

multiple testing were adjusted with BH to correct false discovery rate (FDR) (Benjamini and Yekutieli, 2001). A gene/transcript was significantly DE in a contrast group if it had adjusted $p$-value $<0.01$ and $L_{2} F C \geq 1$.5. Heatmap: Hierarchical clustering was used to partition the DE genes into 10 clusters with euclidean distance and ward.D clustering algorithm (Saracli et al., 2013). ComplexHeatmap R package version 1.20.0 was used to make the heat-map.

Alternative Splicing analysis. At the alternative splicing level, DTU transcripts were determined by comparing the $L_{2} F C$ of a transcript to the weighted average of $L_{2} F C s$ (weights were based on their standard deviation) of all remaining transcripts in the same gene. A transcript was determined as significant DTU if it had adjusted $\mathrm{p}$-value $<0.01$ and $\triangle \mathrm{PS} \geq 0.15$. For DAS genes, each individual transcript $L_{2} F C$ were compared to gene level $L_{2} F C$, which was calculated as the weighted average of $L_{2} F C s$ of all transcripts of the gene. Then $p$-values of individual transcript comparison were summarized to a single gene level p-value with F-test. A gene was significantly DAS in a contrast group if it had an adjusted $p$-value $<0.01$ and any of its transcript had a $\Delta$ Percent Spliced ( $\Delta \mathrm{PS}$ ) ratio $\geq$ 0.15 .

Gene Ontology Analysis. Gene ontology (GO) terms assignment for the DE genes datasets were obtained using the PantherDB tool (http://go.pantherdb.org/index.jsp). An enrichment test was performed for the following categories: BP (biological process), MF (molecular function), and CC (cellular component). $p$-values were obtained using the Fisher exact test and corrected for multiple testing using FDR. The enrichment factor (EF) was estimated as the ratio between the proportions of genes associated with a particular GO category present in the dataset under analysis, relative to the number of genes in this category in the whole transcriptome analyzed. We considered the whole transcriptome as those genes that are expressed at least in one of the evaluated conditions. Bubble plots were generated, using a custom script written in Python language (https://github.com/LucasServi/makeGO), for all those categories for which the adjusted p-value (FDR) was lower than 0.01 .

Chromatin immunoprecipitation (CHIP) assays. ChIP assays were performed on seedlings expressing RSL4-GFP under the native RSL4 promoter, using anti-GFP (Abcam ab290) and anti-IgG (Abcam ab6702) antibodies, mainly as described by Ariel et al. (2020). Seedlings were grown in continuous light at $22^{\circ} \mathrm{C}$ for 10 days, harvested after $24 \mathrm{~h}$ treatment at $10^{\circ} \mathrm{C}$, ground in liquid nitrogen, and resuspended in $25 \mathrm{~mL}$ of nuclear isolation buffer (Bourbousse et al. 2018). Chromatin was crosslinked first with $1.5 \mathrm{mM}$ ethylene glycol bis(succinimidyl succinate) (Thermo Fisher Scientific 21565) for $20 \mathrm{~min}$ at room temperature, and then with formaldehyde at a final concentration of $1 \%$ for 10 min at room temperature. Cross-linking was stopped by adding $1.7 \mathrm{~mL}$ of $2 \mathrm{M}$ glycine and incubating for $10 \mathrm{~min}$ at room temperature. Crosslinked chromatin was extracted by cell resuspension, centrifugation, cell membrane lysis, and sucrose gradient as previously described (Ariel et al., 2020). Nuclei were resuspended in Nuclei Lysis Buffer and chromatin was sonicated using a water bath 
PRX62 and PRX69 regulate $\mathrm{RH}$ growth at low-temperature

Bioruptor Pico (Diagenode; $30 \mathrm{~s}$ on / $30 \mathrm{~s}$ off pulses, at high intensity for 10 cycles). Chromatin samples were incubated for $12 \mathrm{~h}$ at $4{ }^{\circ} \mathrm{C}$ with Protein A Dynabeads (Invitrogen) precoated with the corresponding antibodies. Immunoprecipitated DNA was recovered using Phenol:Chloroform:Isoamilic Acid (25:24:1; Sigma) and analyzed by qPCR. Untreated sonicated chromatin was processed in parallel and considered the Input sample.

SHAM Treatment. Seeds were germinated on agar plates at $22^{\circ} \mathrm{C}$ in a growth chamber in continuous light. After 4 days plants were transferred to agar plates with or without $65 \mu \mathrm{M}$ of SHAM (Salicylhydroxamic acid; Sigma Aldrich, USA), then grown 3 days at $22^{\circ} \mathrm{C}$ followed by 3 days at $10^{\circ} \mathrm{C}$ or 6 days at $22^{\circ} \mathrm{C}$ (control). Root hair phenotype was measured and confocal microscopy analysis was performed.

SS-TOM and SS-TOM-Long-EXT constructs. The binary vector PART27, encoding tdTomato secreted with the secretory signal sequence from tomato polygalacturonase and expressed by the constitutive CaMV 35 S promoter (pART-SS-TOM), was a kind gift of Dr. Jocelyn Rose, Cornell University. The entire reporter protein construct was excised from PART-SS-TOM by digesting with Notl. The resulting fragments were gel-purified with the QIAquick Gel Extraction Kit and ligated using T4 DNA Ligase (New England Biolabs) into dephosphorylated pBlueScript KS+, also digested with Notl and gelpurified, to make pBS-SS-TOM. The plasmid was confirmed by sequencing with primers 35S-FP (5'CCTTCGCAAGACCCTTCCTC-3') and OCS-RP (5'-CGTGCACAACAGAATTGAAAGC-3'). The sequence of the EXT domain from SIPEX1 (NCBI accession AF159296) was synthesized and cloned by GenScript into pUC57 (pUC57-EXT). The plasmid pBS-SS-TOM-Long-EXT was obtained by digesting pUC57-EXT and pBS-SS-TOM with Ndel and SgrAl, followed by gel purification of the 2243 bp band from pUC57EXT and the $5545 \mathrm{bp}$ band from pBS-SS-TOM, and ligation of the two gel-purified fragments. The pBSSS-TOM-Long-EXT plasmid was confirmed by sequencing with 35S-FP, OCS-RP, and tdt-seq-FP (5'CCCGTTCAATTGCCTGGT-3'). Both pBS plasmids were also confirmed by digestion. The binary vector pART-SS-TOM-Long-EXT was made by gel purifying the Notl insert fragment from the pBS-SS-TOMLong EXT plasmid and ligating it with PART-SS-TOM backbone that had been digested with Notl, gel purified, and dephosphorylated. This plasmid was confirmed by sequencing. The construct SS-TOM and SS-TOM-Long-EXT where transformed into Arabidopsis plants. The secretory sequence (SS) from tomato polygalacturonase is MVIQRNSILLLIIIFASSISTCRSGT (2.8kDa) and the EXT-Long domain sequence

BAAAAAAACTLPSLKNFTFSKNIFESMDETCRPSESKQVKIDGNENCLGGRSEQRTEKECFPVVSKPVDCSKGHCG VSREGQSPKDPPKTVTPPKPSTPTTPKPNPSPPPPKTLPPPPKTSPPPPVHSPPPPPVASPPPPVHSPPPPVASPPPP VHSPPPPPVASPPPPVHSPPPPVASPPPPVHSPPPPVHSPPPPVASPPPPVHSPPPPVHSPPPPVHSPPPPVHSPP PPVHSPPPPVASPPPPVHSPPPPVHSPPPPVHSPPPPVASPPPPVHSPPPPPPVASPPPPVHSPPPPVASPPPPVH SPPPPVASPPPPVHSPPPPVHSPPPPVHSPPPPVASPPPALVFSPPPPVHSPPPPAPVMSPPPPTFEDALPPTLGSL 
PRX62 and PRX69 regulate $\mathrm{RH}$ growth at low-temperature

YASPPPPIFQGY* 395-(39.9kDa). The predicted molecular size for SS-TOM protein is $54.2 \mathrm{kDa}$ and for SS-TOM-EXT-Long Mw is $97.4 \mathrm{kDa}$.

\section{Acknowledgements}

541 We would like to thank Margaret Fleming and Patricia Bedinger for sharing SS-TOM-Long-EXT and SS-

542 TOM constructs and Jorge Muschietti for his valuable comments on this work. We thank NASC (Ohio

543 State University) for providing T-DNA lines seed lines. J.M.E., C.M.F., E.P., J.B are investigators of the

544 National Research Council (CONICET) from Argentina. This work was supported by grants from

545 ANPCYT (PICT2017-0066, and PICT2019-0015 to J.M.E). In addition, this research was also funded by

546 ANID - Programa Iniciativa Científica Milenio ICN17_022 and Fondo Nacional de Desarrollo Científico

547 y Tecnológico [1200010] to J.M.E.

\section{Author Contribution}

550 J.M.P. performed most of the experiments and analysed the data. P.R. measured the peroxidase 551 activity and PRXs expression in single prx mutants and selected accessions, analysed the subcellular 552 localization of PRXs, cloned the PRXs, generated 35SproPRXs constructs, produced the RNA-seq data. 553 L.K performed GWAS measurements. C.M.F. performed GWAS and haplotype analysis. L.S., R.T, C.M, 554 and E.P. performed the bioinformatics analysis. V.B.G., J.M.P., C.B., E.M., D.R.R.G, Y.R., M.C., analysed 555 part of the data. J.B and M.Y. provided the accessions and analysed the data. L.S, P.T., E.P., C.M. 556 analysed the RNA-seq data. In addition, L.S and E.P. analysed the alternative splicing. L.F. and F.A. 557 performed the CHIP assay. C.D. produced the RNA-seq data and analysed the results. J.M.E. designed 558 research, analysed the data, supervised the project, and wrote the paper. All authors commented on 559 the results and the manuscript. This manuscript has not been published and is not under 560 consideration for publication elsewhere. All the authors have read the manuscript and have approved 561 this submission.

562

\section{Competing financial interest}

564 The authors declare no competing financial interests. Correspondence and requests for materials 565 should be addressed to J.M.E. (Email: jestevez@leloir.org.ar). 
bioRxiv preprint doi: https://doi.org/10.1101/2021.08.20.456256; this version posted August 20, 2021. The copyright holder for this preprint (which was not certified by peer review) is the author/funder, who has granted bioRxiv a license to display the preprint in perpetuity. It is made available under aCC-BY-NC-ND 4.0 International license.

PRX62 and PRX69 regulate RH growth at low-temperature

A
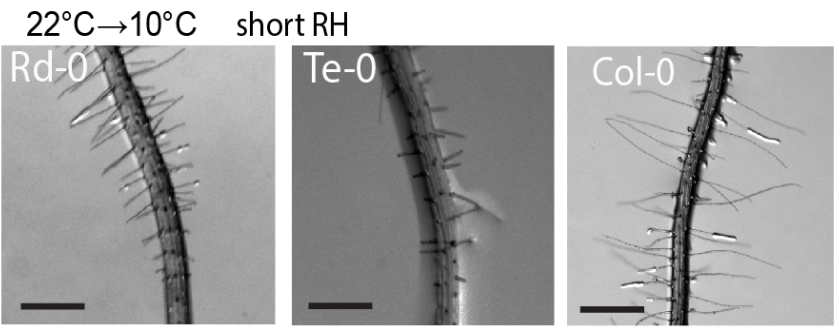

$22^{\circ} \mathrm{C} \rightarrow 10^{\circ} \mathrm{C} \quad$ long $\mathrm{RH}$

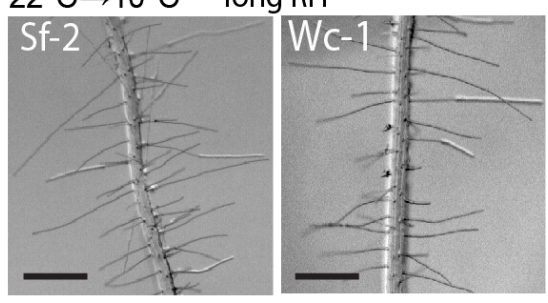

B $22^{\circ} \mathrm{C}$
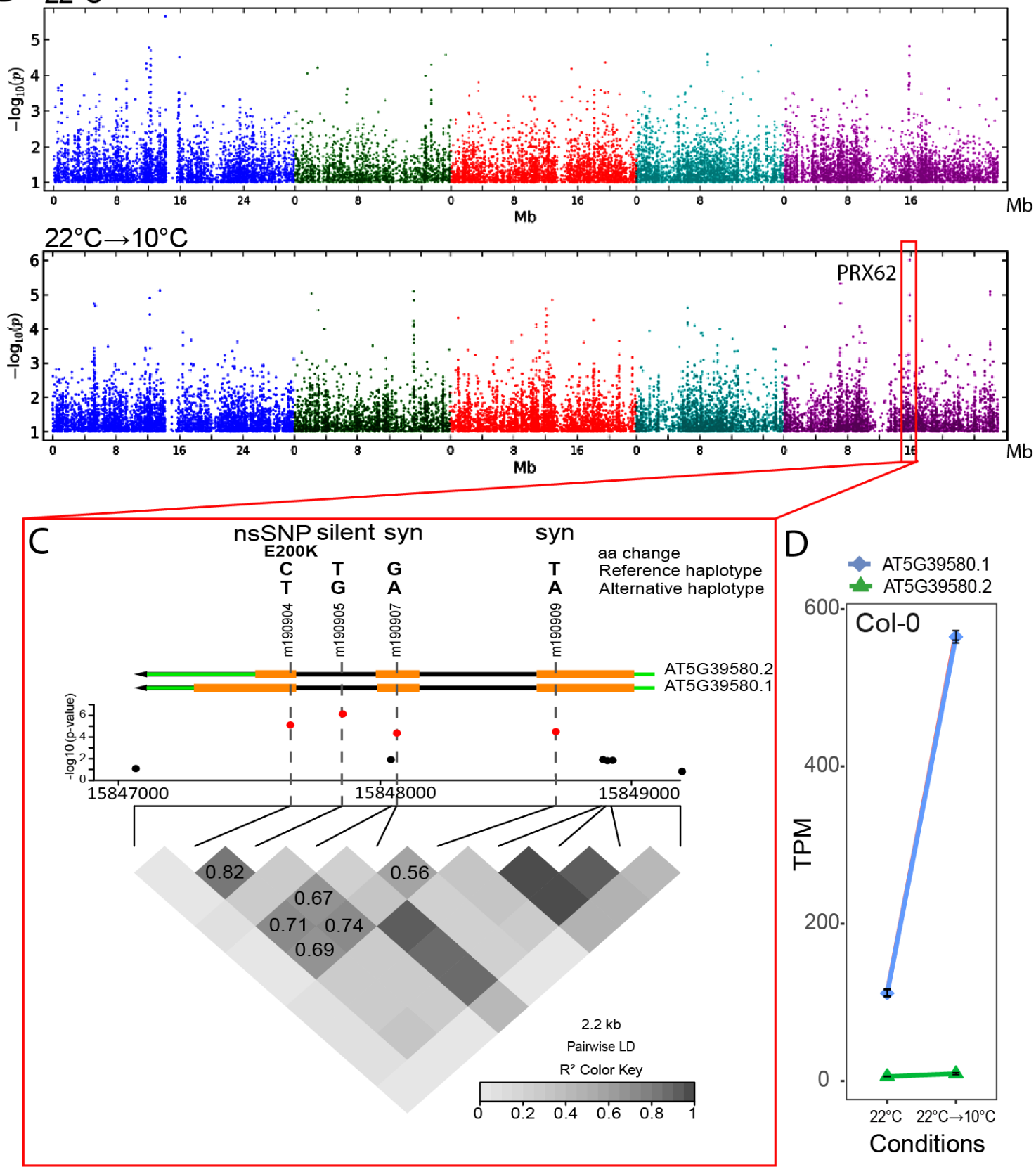

Figure 1. PRX62 associates with enhanced RH growth under low-temperature condition. 
PRX62 and PRX69 regulate $\mathrm{RH}$ growth at low-temperature

(A) Representative accessions of $A$. thaliana showing short ( $\mathrm{Rd}-0$ and $\mathrm{Te}-0)$ and long root hair $(\mathrm{RH})$ phenotypes (Col-0, Sf-2 and Wc-1) when grown at low temperature $\left(10^{\circ} \mathrm{C}\right)$.

(B) Manhattan plots for $\mathrm{RH}$ length at $22^{\circ} \mathrm{C}$ (top plot) and at $10^{\circ} \mathrm{C}$ (bottom plot). Coarse analysis was performed using GWAPP (https://gwapp.gmi.oeaw.ac.at/). Arabidopsis chromosomes are depicted in different colors. The red box in the bottom plot indicates the genomic region significantly associated with root hair length at $10^{\circ} \mathrm{C}$.

(C) Zoomed-in of the genomic region red-boxed in (B). The lead SNP (m190905) and three additional SNPs highly associated with RH length localize within PRX62 (AT5G39580). PRX62 splice variants (AT5G39580.1, AT5G39580.2) are depicted in green-orange-black arrows. The four associated SNPS (in red) are in high linkage disequilibrium (LD) with each other, and they are combined into two major and opposite haplotypes in the population (CTGT and TGAA). LD plot is shown as heat-map at the bottom. Haplotypes and type of mutation for these SNPs are indicated at the top of the figure. The SNP m190904 is a non-synonymous SNP for AT5G39580.2 causing a change from Glutamic Acid to Lysine at position 200 (E200K) in the amino acid sequence.

(D) The full-length variant of PRX62 (AT5G39580.1) is upregulated at low-temperature $\left(10^{\circ} \mathrm{C}\right)$ while the shorter variant (AT5G39580.2) is almost not detected. Expression measured by RNA-seq of PRX62. TPM = Transcripts Per Kilobase Million. 
PRX62 and PRX69 regulate RH growth at low-temperature
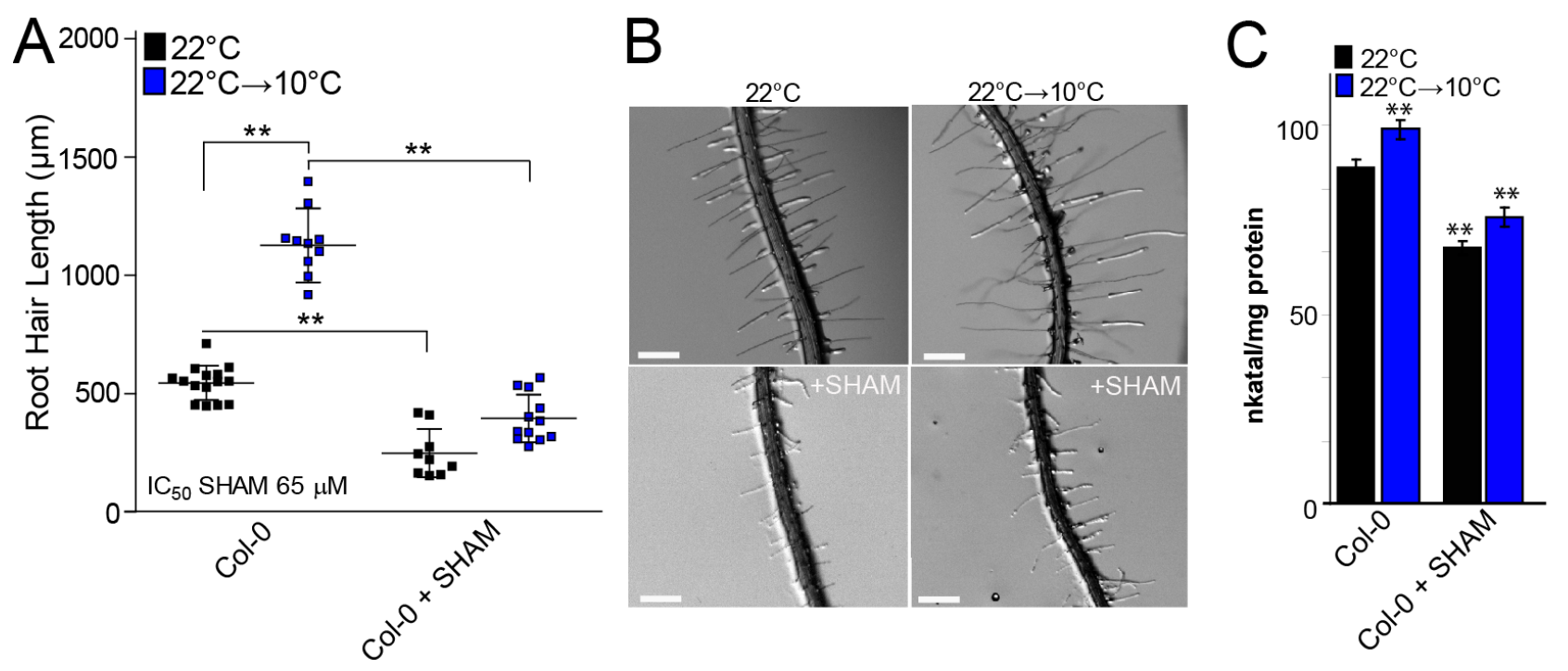

\section{$\mathrm{D}$}

listorms AT5G39580.1

AT5G39580.2

PRX62 (AT5G39580)
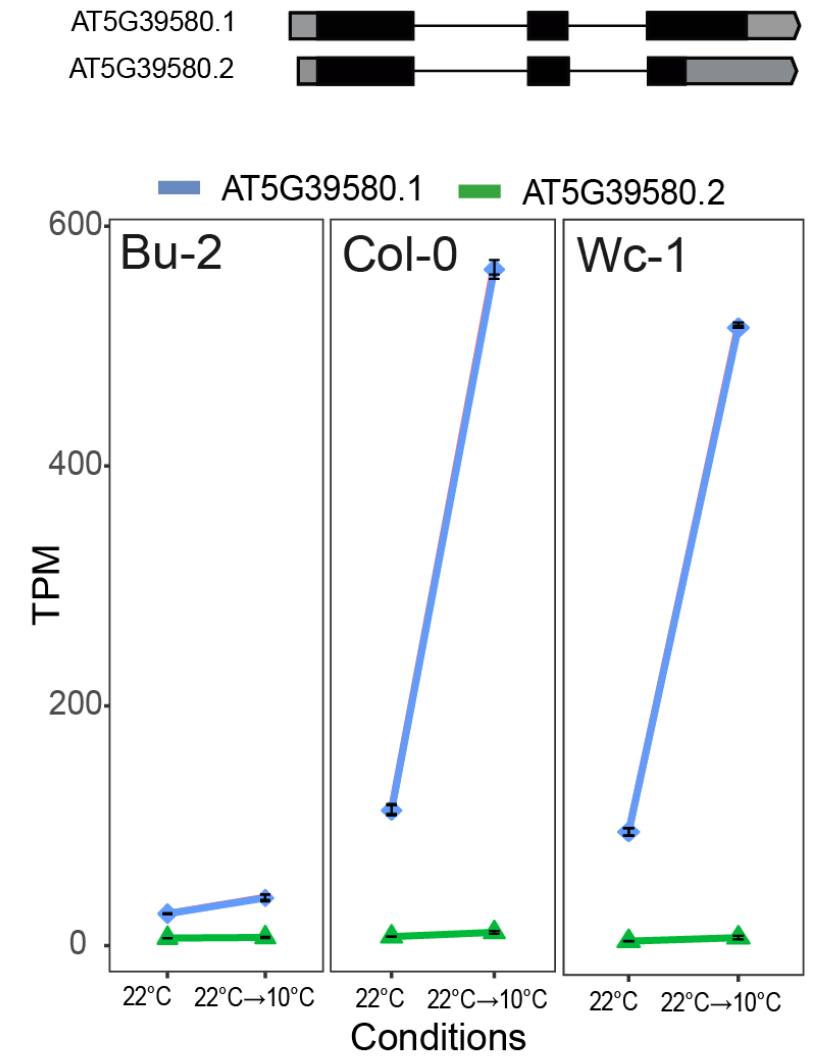

RH growth
Isoforms $\quad$ PRX69 (AT5G64100)

AT5G64100.1

AT5G64100.2
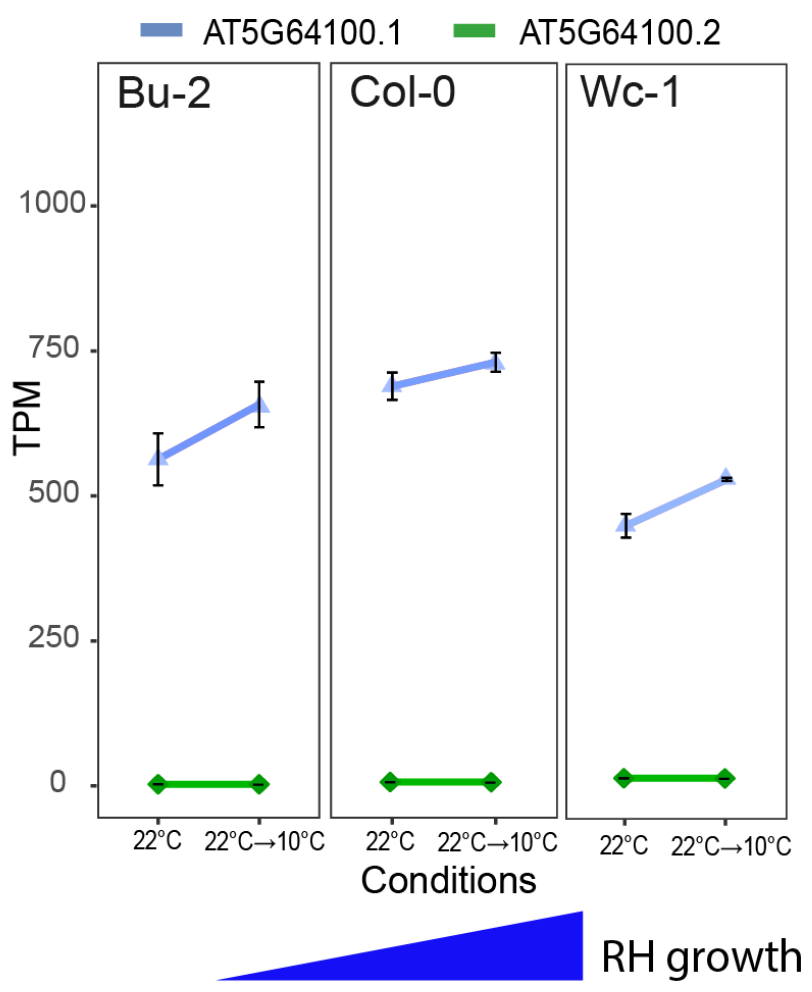

Figure 2. Low-temperature enhanced RH growth requires peroxidase activity and upregulates PEROXIDASE 62 (PRX62) expression. 
PRX62 and PRX69 regulate RH growth at low-temperature

(A) RH length phenotype of Col- 0 at $22^{\circ} \mathrm{C}$ or $10^{\circ} \mathrm{C}$, with or without the addition of the PRX inhibitor SHAM. Inhibitory Concentration 50 (IC $\left.\mathrm{C}_{50}\right)$ of $\mathrm{RH}$ grown at $22^{\circ} \mathrm{C}$ was used $(65 \mu \mathrm{M})$. $\mathrm{RH}$ length values are the mean of three replicates \pm SD. P-value of one-way ANOVA, $(* *) P<0.01$.

(B) Representative images of RH phenotype of Col-0 quantified in (A). Scale bars $=0.5 \mathrm{~mm}$.

(C) Total root peroxidase activity. Peroxidase activity was assayed using guaiacol/hydrogen peroxide as substrate in root tissues grown with or without $65 \mu \mathrm{M} \mathrm{SHAM}$, either for 5 days at $22^{\circ} \mathrm{C}$ or for 5 days at $22^{\circ} \mathrm{C}$ plus 3 days at $10^{\circ} \mathrm{C}$. Enzyme activity values (expressed as nkatal/mg protein) are the mean of three replicates \pm SD. P-value of one-way ANNOVA, $(* *) P<0.01$.

(D) In contrast to $P R X 69, P R X 62$ is differentially expressed at low temperature $\left(10^{\circ} \mathrm{C}\right)$ in Arabidopsis accessions with contrasting RH phenotypes. Expression measured by RNA-seq of $P R X 62$ and $P R X 69$ in three contrasting Arabidopsis accessions based on the RH phenotype (short RH in Bu-2 and extra-long $\mathrm{RH}$ in Col-0 and $\mathrm{Wc}-1)$ detected at $10^{\circ} \mathrm{C}$. Isoforms' schemes were adapted from boxify (https://boxify.boku.ac.at/). TPM = Transcripts Per Kilobase Million. 
PRX62 and PRX69 regulate RH growth at low-temperature

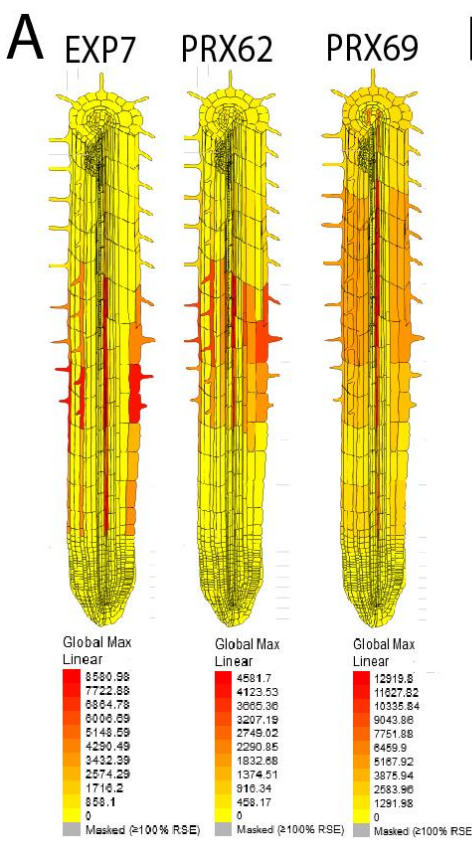

C

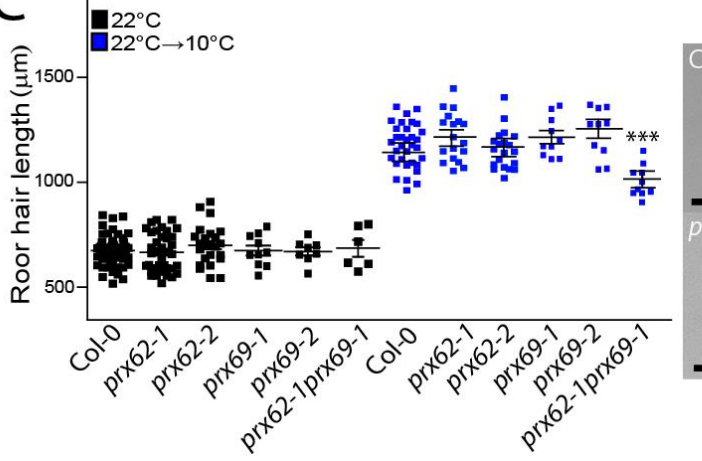

$\mathrm{E}$

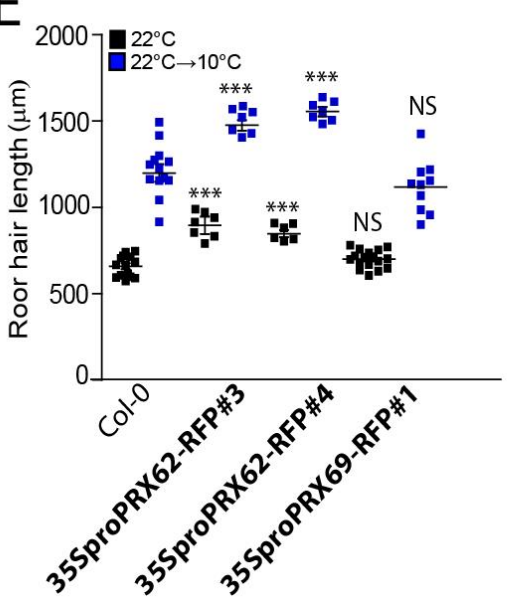

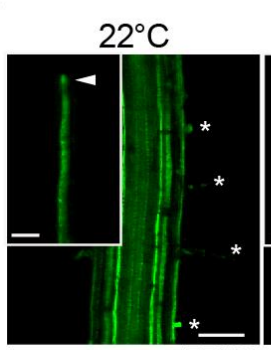

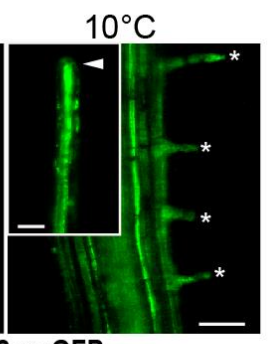

PRX62proGFP

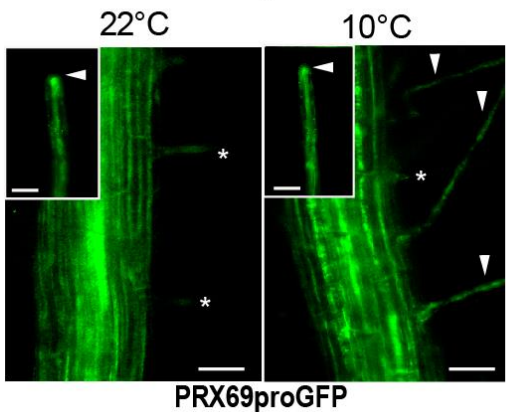

PRX69proGFP

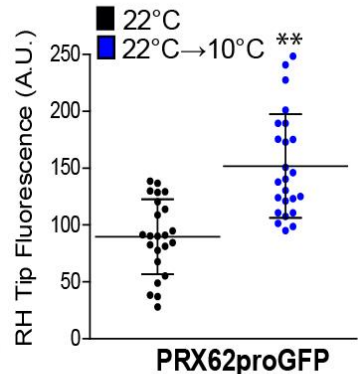

PRX62proGFP
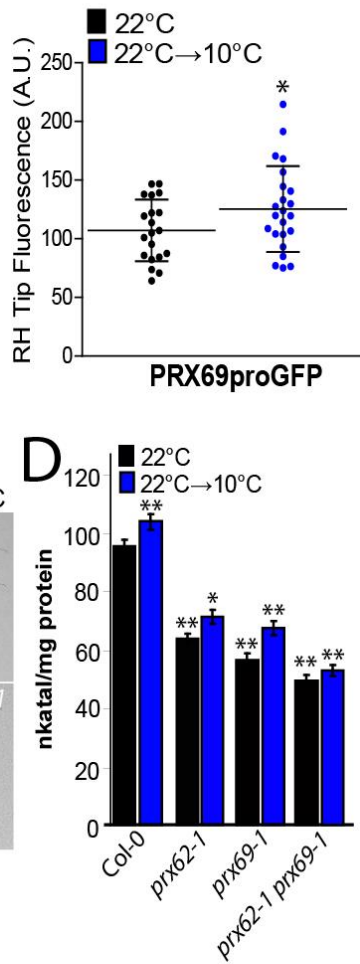

Figure 3. PEROXIDASE 62 (PRX62) and PEROXIDASE 69 (PRX69) regulate RH growth and peroxidase activity under low-temperature conditions. 
PRX62 and PRX69 regulate $\mathrm{RH}$ growth at low-temperature

(A) The in silico analysis of $P R X 62$ and $P R X 69$ gene expression using Tissue Specific Root eFP (http://bar.utoronto.ca/eplant/). The RH marker EXPANSIN 7 was included for comparison.

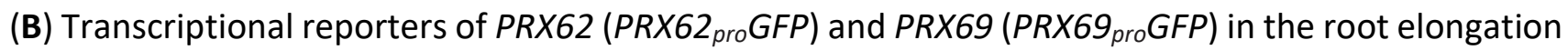
zone and specifically in $\mathrm{RHs}(\mathrm{RH})$ grown at $22^{\circ} \mathrm{C}$ or $10^{\circ} \mathrm{C}$. Scale bar $=200 \mu \mathrm{m}$. Growing RHs are indicated with asterisks while already grown $\mathrm{RHs}$ with arrowheads. On the right, GFP signal is quantified. Fluorescence AU were reported as the mean of three replicates \pm SD. P-value of one-way ANOVA, $(* *) \mathrm{P}<0.01,\left(^{*}\right) \mathrm{P}<0.05$.

(C) Scatter-plot of RH length of Col-0, PRX62 mutants (prx62-1 and prx62-2) and PRX69 mutants (prx69-1 and prx69-2) and double mutant prx62-1 prx69-1 grown at $22^{\circ} \mathrm{C}$ or at $10^{\circ} \mathrm{C}$. RH length values are the mean of three replicates \pm SD. P-value of one-way ANOVA, $(* * *) P<0.001$.

(D) Peroxidase activity was assayed using guaiacol/hydrogen peroxide as substrate in root tissues from Col-0, prx62-1 and prx69-1 seedlings grown either at $22^{\circ} \mathrm{C}$ or $10^{\circ} \mathrm{C}$. Enzyme activity values (expressed as nkatal/mg protein) are the mean of three replicates \pm SD. P-value of one-way ANOVA, $(* *) \mathrm{P}<0.001,\left(^{*}\right) \mathrm{P}<0.05$.

(E) Scatter-plot of RH length of Col-0, 35S pro $P R X 62 / \mathrm{Col}-0$ and 35S pro $P R X 69 / \mathrm{Col}-0$ lines. RH length values are the mean of three replicates \pm SD. P-value of one-way ANOVA, $\left(^{* * *}\right) P<0.001$. NS= nonsignificant differences. 
bioRxiv preprint doi: https://doi.org/10.1101/2021.08.20.456256; this version posted August 20, 2021. The copyright holder for this preprint (which was not certified by peer review) is the author/funder, who has granted bioRxiv a license to display the preprint in perpetuity. It is made available under aCC-BY-NC-ND 4.0 International license.

PRX62 and PRX69 regulate $\mathrm{RH}$ growth at low-temperature

\section{A}

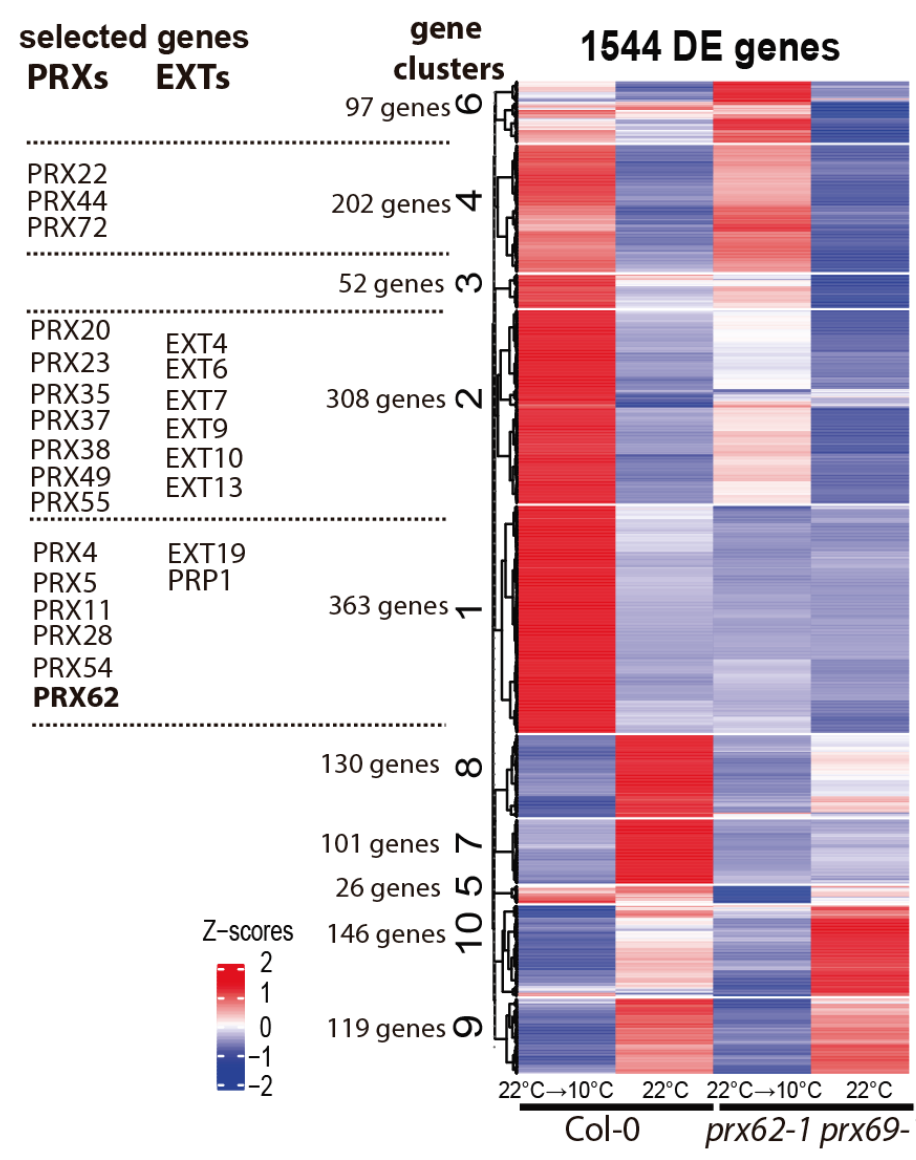

GO cellular Components Clusters 124

2.

cell wall (GO:0005618)

external encapsulating structure (GO:0030312)

extracellular region (GO:0005576)

protein-containing complex (GO:0032991)

intracellular non-membrane-bounded organelle (GO:0043232)

non-membrane-bounded organelle (GO:0043228)

nucleus (GO:0005634)

organelle membrane (GO:0031090)

catalytic complex (GO:1902494)

intracellular anatomical structure (GO:0005622)

membrane-bounded organelle (G0:0043227)

intracellular membrane-bounded organelle (GO:0043231)

organelle (GO:0043226)

intracellular organelle (GO:0043229)

FDR Fold Enrichment

- $0.002 \bigcirc 1$

- $0.004 \bigcirc 2$

- 0.006

- 0.008

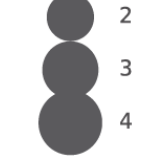

PRP1 (AT1G54970)

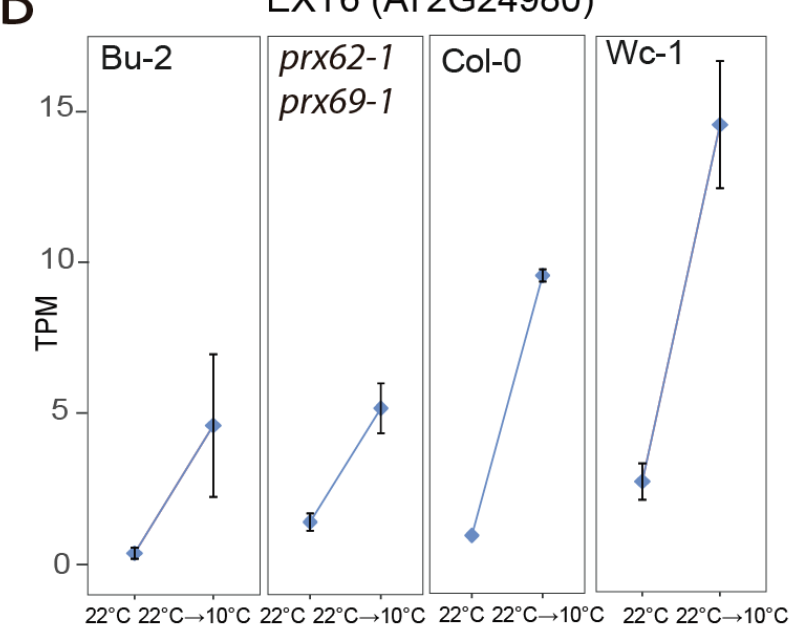

$\mathrm{RH}$ growth at $10^{\circ} \mathrm{C}$

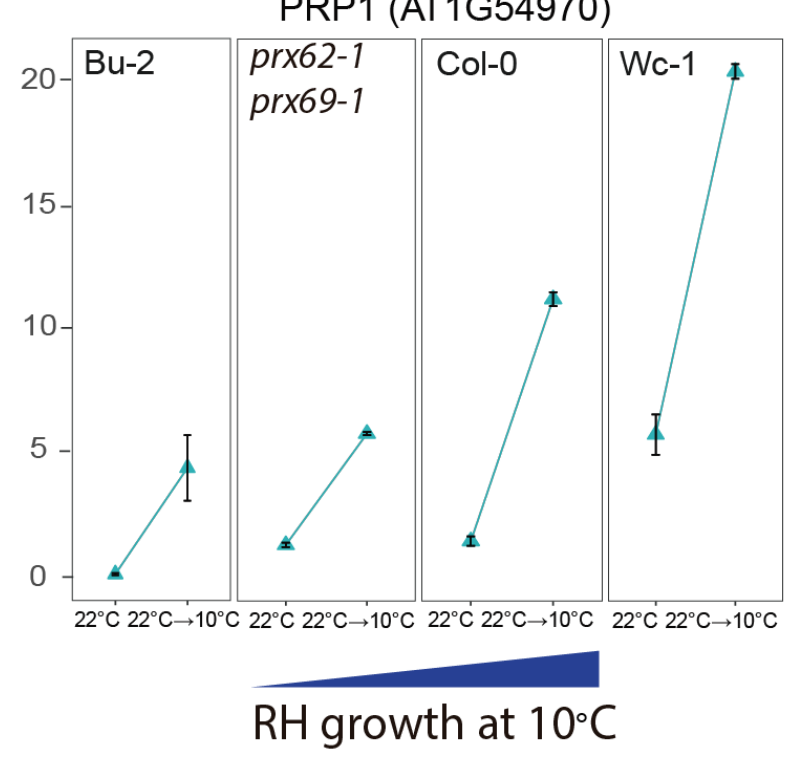

Figure 4. Global transcriptomic changes induced by low-temperature and misregulated in the prx62 prx69 mutant are associated with PRXs and cell associated-EXTs. 
PRX62 and PRX69 regulate $\mathrm{RH}$ growth at low-temperature

(A) Heat-map showing the hierarchical gene clustering for 1,544 A. thaliana genes differentially expressed $(\mathrm{DE})$ between room temperature growth $\left(22^{\circ} \mathrm{C}\right)$ and low-temperature $\left(10^{\circ} \mathrm{C}\right)$ growth in wild type Col-0 and in double mutant prx62-1 prx69-1 roots. Gene Ontology analysis results depicting the top 7 most significantly enriched GO terms are shown as bubble plots on the right for the clusters of interest. DE genes in clusters 1, 2 and 4 were contrasted against all the expressed genes for GO analysis. The size of the points reflects the amount of gene numbers enriched in the GO term. The color of the points means the $p$ value. Relevant gene examples of specific clusters $(1,2$ and 4$)$ are listed on the left.

(B) Expression of EXT6 and PRP1 is gradually upregulated at low temperature $\left(10^{\circ} \mathrm{C}\right)$ in 4 genotypes from very short RHs (Bu-2) to very long RHs (Wc-1) (RNA-seq data). TPM = Transcripts Per Kilobase Million. 
PRX62 and PRX69 regulate $\mathrm{RH}$ growth at low-temperature
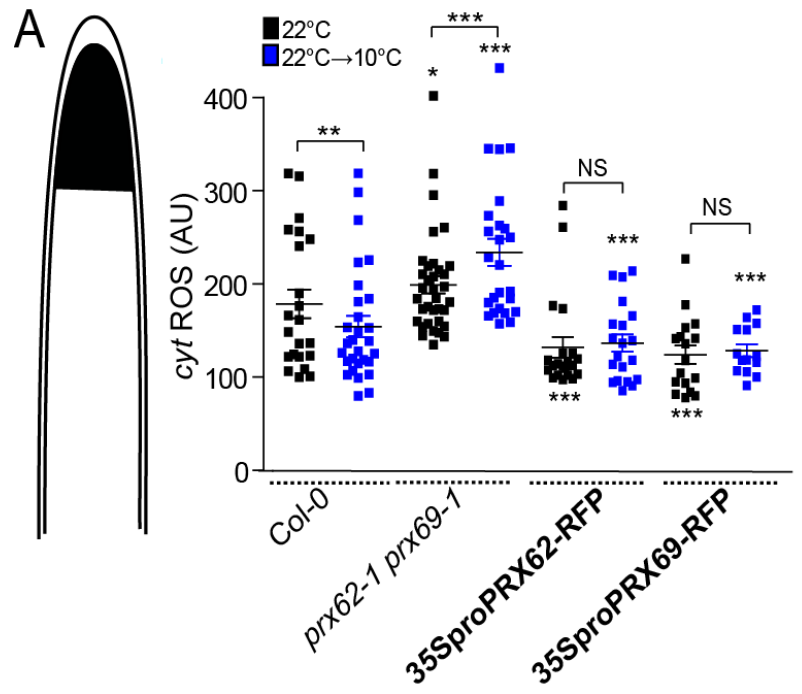

C

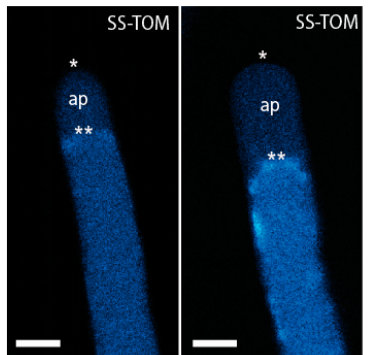

$$
22^{\circ} \mathrm{C}
$$$$
22^{\circ} \mathrm{C} \rightarrow 10^{\circ} \mathrm{C}
$$
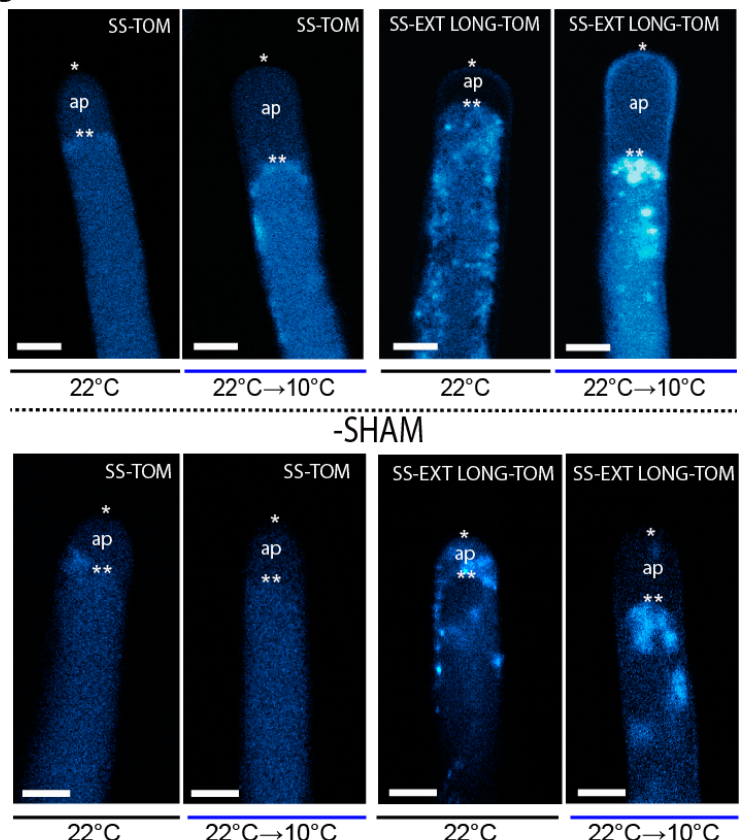
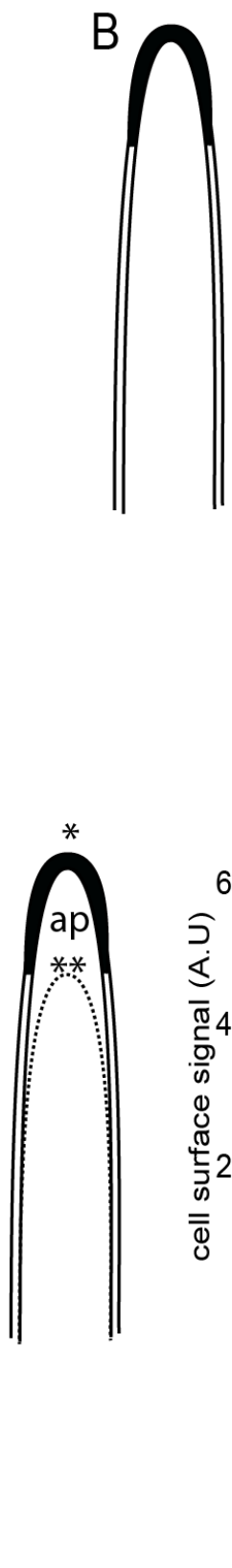
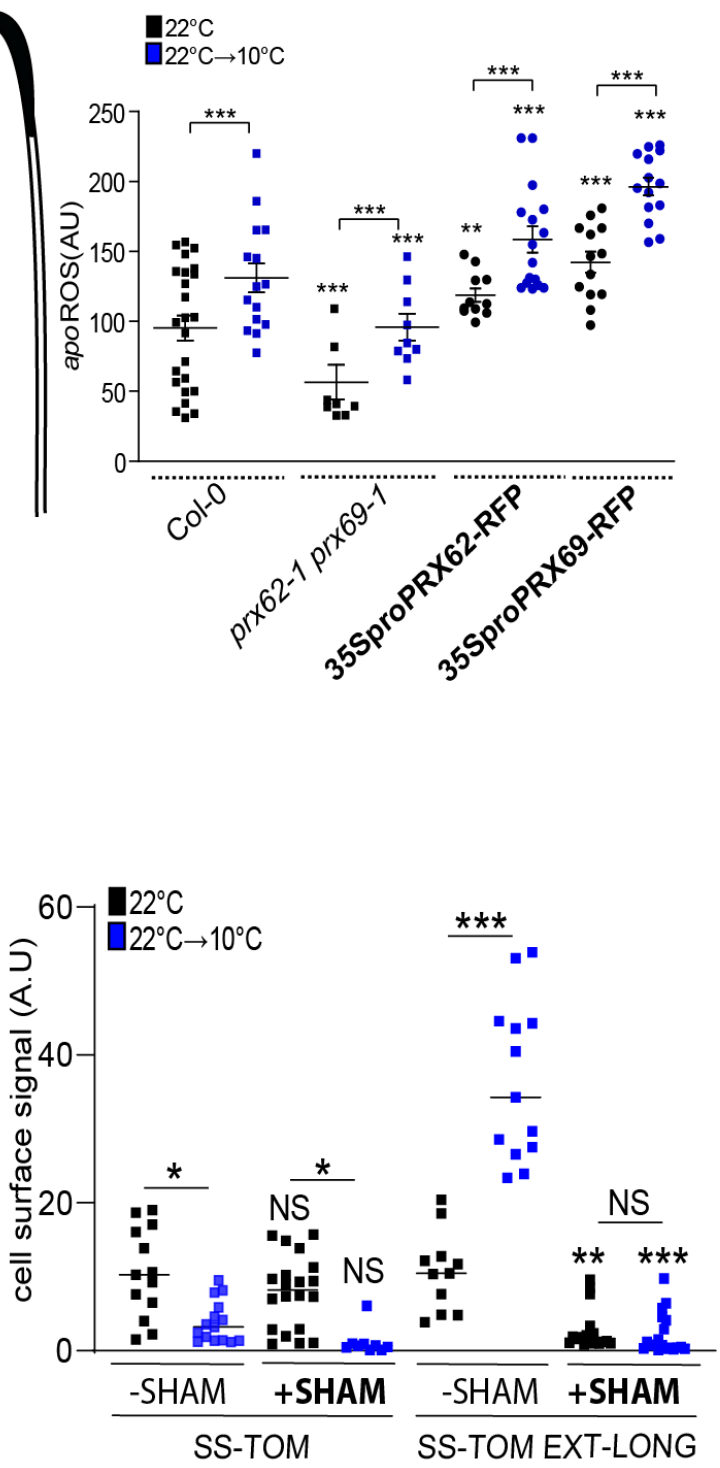

Figure 5. ROS-homeostasis and EXT-stabilization in RH apical cell wall depend on PRX62 and PRX69. (A) Cytoplasmic ROS (cytROS) levels were measured using 2', 7'-dichlorodihydrofluorescein diacetate $\left(\mathrm{H}_{2}\right.$ DCF-DA) in apical areas of RHs in wild-type (Columbia Col-0), in the double mutant prx62-1 prx691 and in the $35 S_{\text {pro }} P R X 62 / \mathrm{Col}-0$ and $35 S_{\text {pro }} P R X 69 / \mathrm{Col}-0$ lines grown at $22^{\circ} \mathrm{C}$ or $10^{\circ} \mathrm{C}$. Measurements are the mean of three replicates $\pm \mathrm{SD}$. P-value of one-way ANOVA, $\left({ }^{*}\right) \mathrm{P}<0.1,\left(^{* *}\right) \mathrm{P}<0.01,\left({ }^{* * *}\right)$ $P<0.001$. NS $=$ non-significant differences.

(B) Apoplastic ROS (apoROS) levels were measured with Amplex ${ }^{\mathrm{TM}}$ UltraRed in apical areas of RHs in wild-type (Columbia Col-0), in the double mutant prx62-1 prx69-1 and in the $35 S_{\text {pro }} P R \times 62 /$ Col-0 and 
PRX62 and PRX69 regulate $\mathrm{RH}$ growth at low-temperature

$35 S_{\text {pro }} P R X 69 / \mathrm{Col}-0$ lines grown at $22^{\circ} \mathrm{C}$ or $10^{\circ} \mathrm{C}$. Measurements are the mean of three replicates $\pm \mathrm{SD}$. P-value of one-way ANOVA, (**) P<0.01, (***) $\mathrm{P}<0.001$.

(C) Signal of SS-TOM and SS-EXT LONG-TOM in the apical zone of RHs grown at $22^{\circ} \mathrm{C}$ or $10^{\circ} \mathrm{C}$ with or without SHAM treatment in Col-0. Cells were plasmolyzed with mannitol $8 \%$. In the images: $(*)$ indicates cell surface including the plant cell walls, $\left({ }^{* *}\right)$ indicates the retraction of the plasma membrane, (ap) apoplastic space delimitated between the plant cell wall and the retracted plasma membrane. (A.U.) = Arbitrary Units. Fluorescence $A U$ were reported as the mean of three replicates \pm SD. P-value of one-way ANOVA, $\left({ }^{*}\right) \mathrm{P}<0.05,(* *) \mathrm{P}<0.01,(* * *) \mathrm{P}<0.001$. NS= non-significant differences. 
PRX62 and PRX69 regulate RH growth at low-temperature
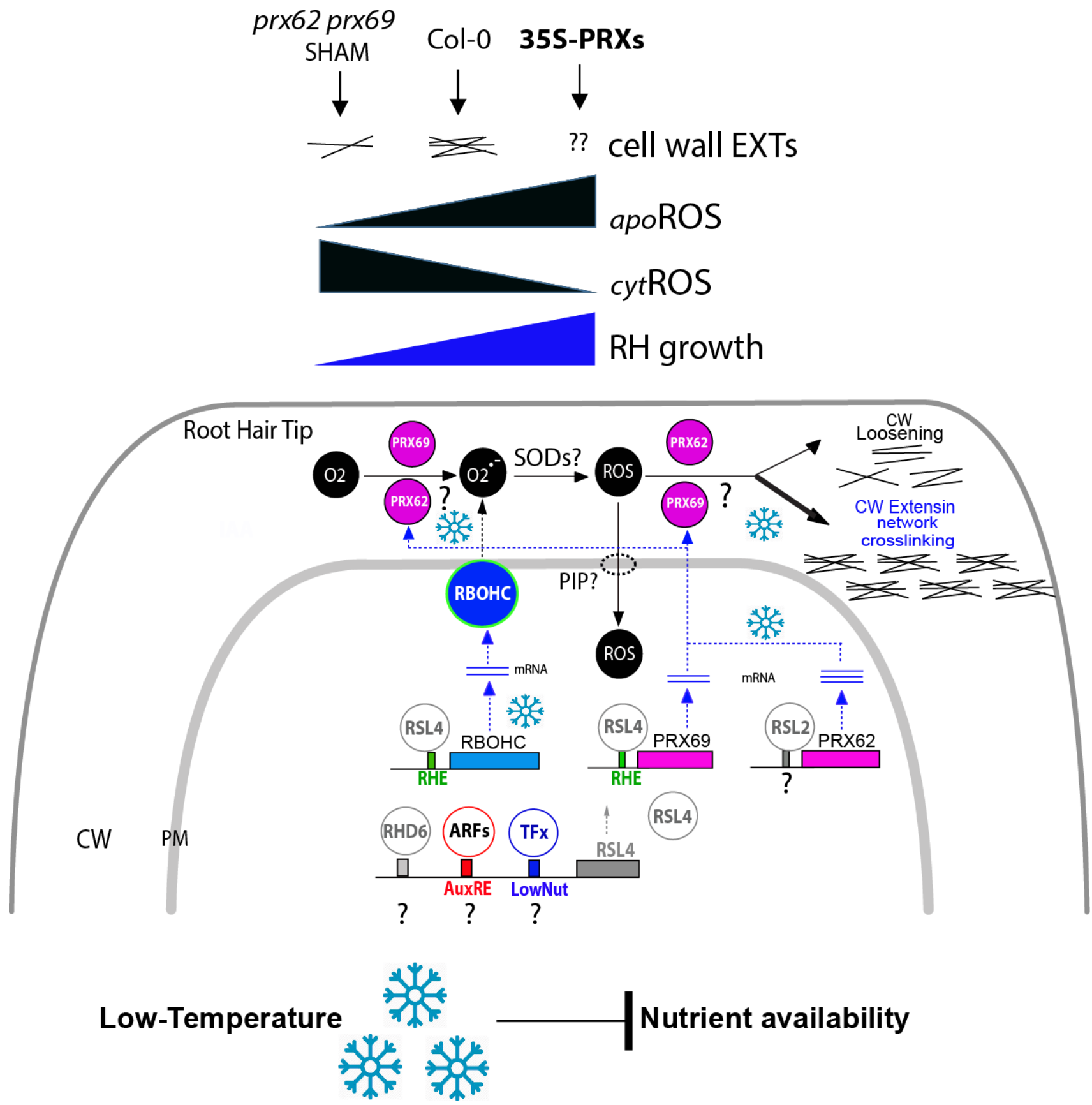

Figure 6. Proposed Model of PRX62 and PRX69 functions in ROS-homeostasis and EXT-cell wall association linked to $\mathbf{R H}$ growth at low-temperature. This model is based on the results presented in this study and in previous works (Mangano et al. 2017; Marzol et al. 2021; Moison et al. 2021). ROS-homeostasis (apoROS + cytROS) in the RH tip. Higher apoROS/low cytROS than Col-0 present in

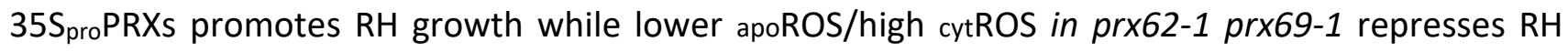
growth at low-temperature. Changes in apoROS triggered by PRX62 and PRX69 might control changes in the EXT-mediated cell wall expansion/crosslinking in the apical RH zone. Part of the apoROS might 
PRX62 and PRX69 regulate RH growth at low-temperature

be translocated to the cytoplasm to contribute to the cytROS helped by Plasma membrane Intrinsic Proteins (PIPS). Finally, at the transcriptional level, RSL4 directly regulates PRX69 expression and indirectly PRX62 at low-temperature. How RSL4 is regulated under low-temperature remains to be established. Auxin, RHD6, and/or an unknow TF are the most probable regulators of RSL4 expression at low temperature in $\mathrm{RHs}$. AuxRE=Auxin response element. Low-Nut= low nutrient putative ciselement; RHE= Root Hair E-box. TFx= unknown TF. 
bioRxiv preprint doi: https://doi.org/10.1101/2021.08.20.456256; this version posted August 20, 2021. The copyright holder for this preprint (which was not certified by peer review) is the author/funder, who has granted bioRxiv a license to display the preprint in perpetuity. It is made available under aCC-BY-NC-ND 4.0 International license.

PRX62 and PRX69 regulate $\mathrm{RH}$ growth at low-temperature

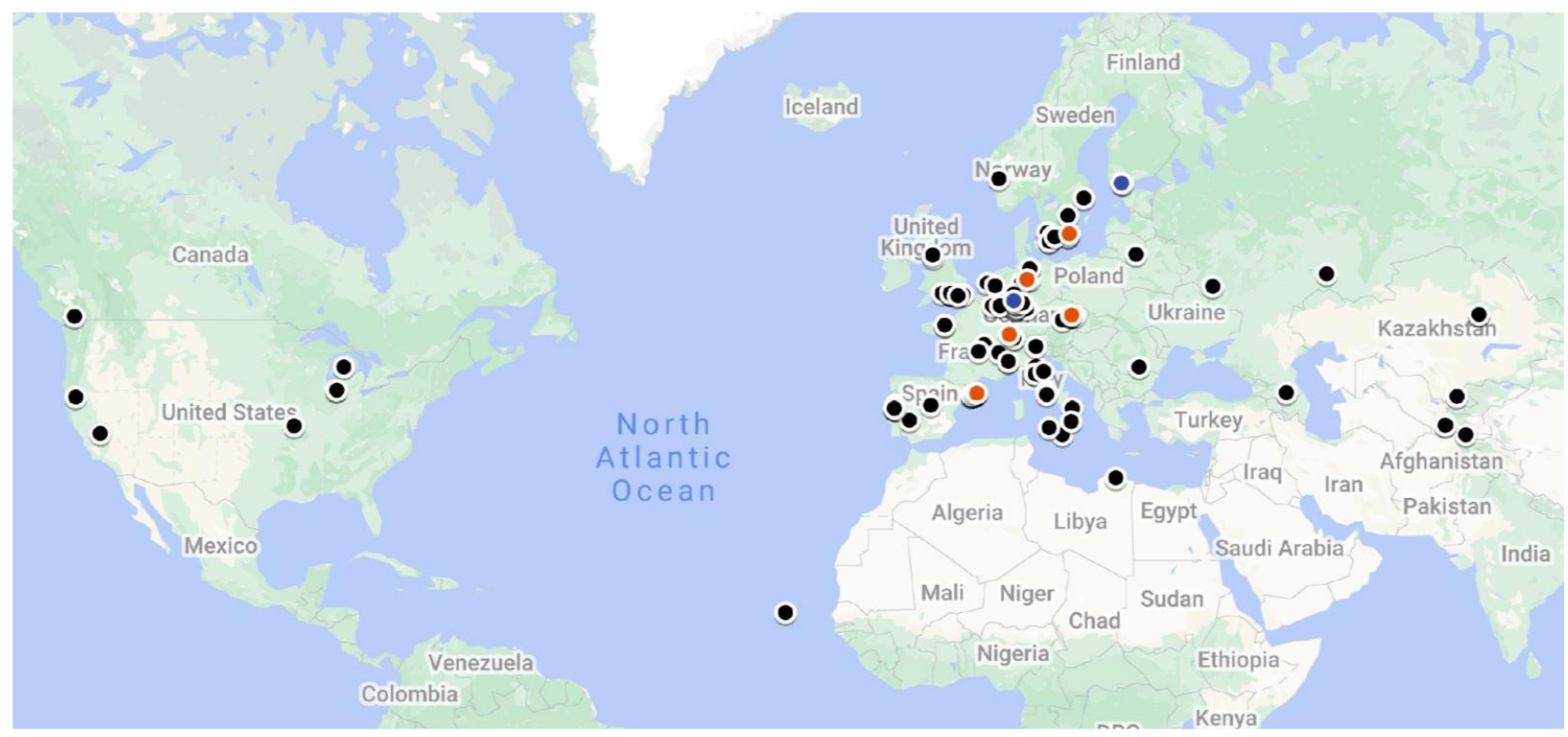

Figure S1. Geographic location of the 106 Arabidopsis thaliana accessions used in this study.

Each dot represents the sampling original site of individual accession used for this study. In red color, 5 accessions with the longest $\mathrm{RHs}$ at $10^{\circ} \mathrm{C}$, and in blue those with the shortest $\mathrm{RHs}$ at $10^{\circ} \mathrm{C}$. 
PRX62 and PRX69 regulate RH growth at low-temperature
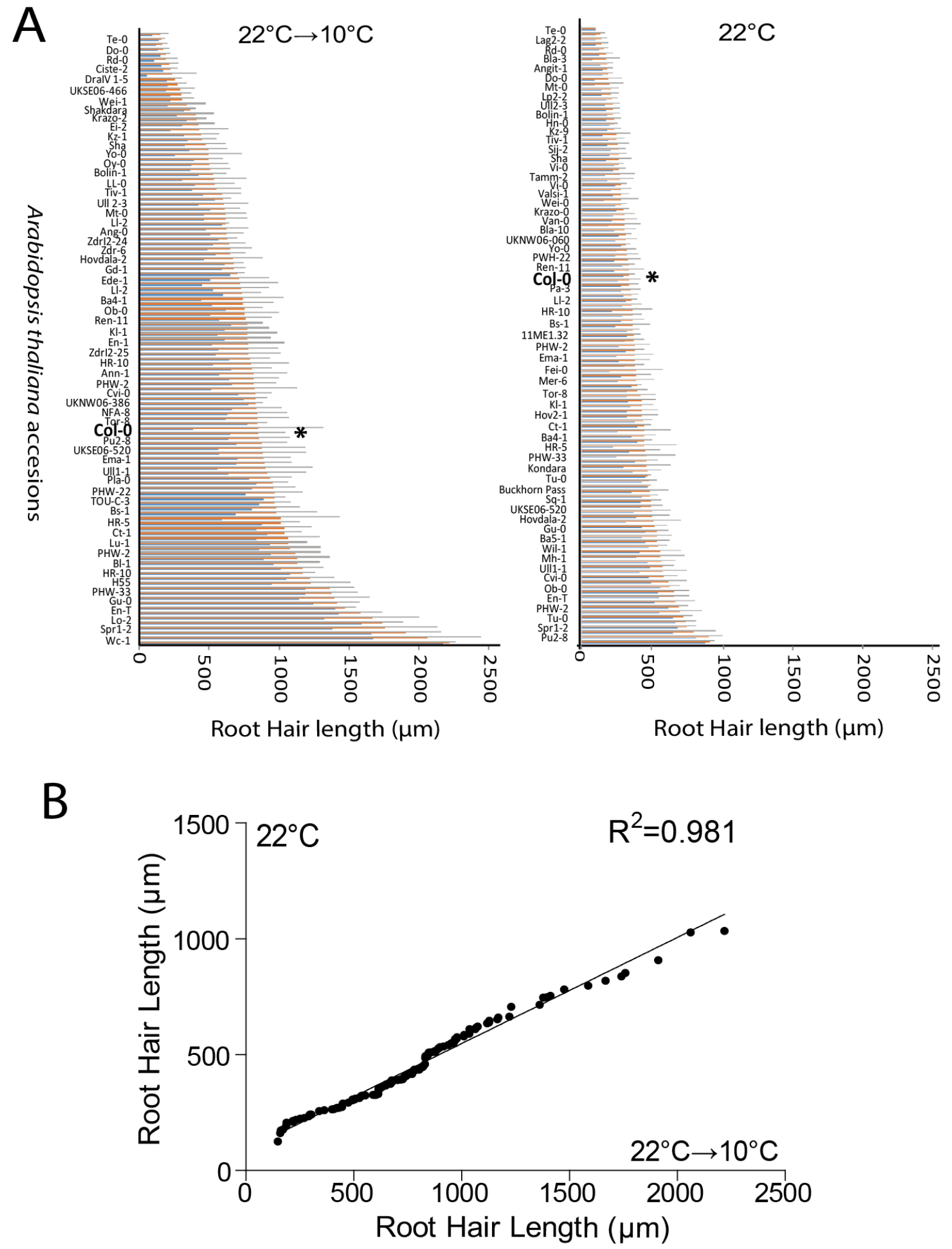

Figure S2. $\mathrm{RH}$ cell growth phenotype in Arabidopsis accessions at $22^{\circ} \mathrm{C} \rightarrow 10^{\circ} \mathrm{C}$ versus at $22^{\circ} \mathrm{C}$. 
PRX62 and PRX69 regulate $\mathrm{RH}$ growth at low-temperature

(A) RH length phenotype in the Arabidopsis accessions at $22^{\circ} \mathrm{C} \rightarrow 10^{\circ} \mathrm{C}$ versus at $22^{\circ} \mathrm{C}$. Average cell length on 50-300 fully elongated RHs is indicated ( \pm SD) ( $N=$ root 5-30). Col-0 is indicated with an asterisk $\left({ }^{*}\right)$. Only 61 accessions are indicated in the edited graphs to improve readability. Average cell length (in orange), highest (in grey) and lowest (blue) values are shown.

(B) Pearson correlation $\left(\mathrm{R}^{2}=0.981\right)$ between $\mathrm{RH}$ growth of Arabidopsis accessions grown at $22^{\circ} \mathrm{C}$ versus the same accessions grown at $22^{\circ} \mathrm{C} \rightarrow 10^{\circ} \mathrm{C}$. 
PRX62 and PRX69 regulate $\mathrm{RH}$ growth at low-temperature

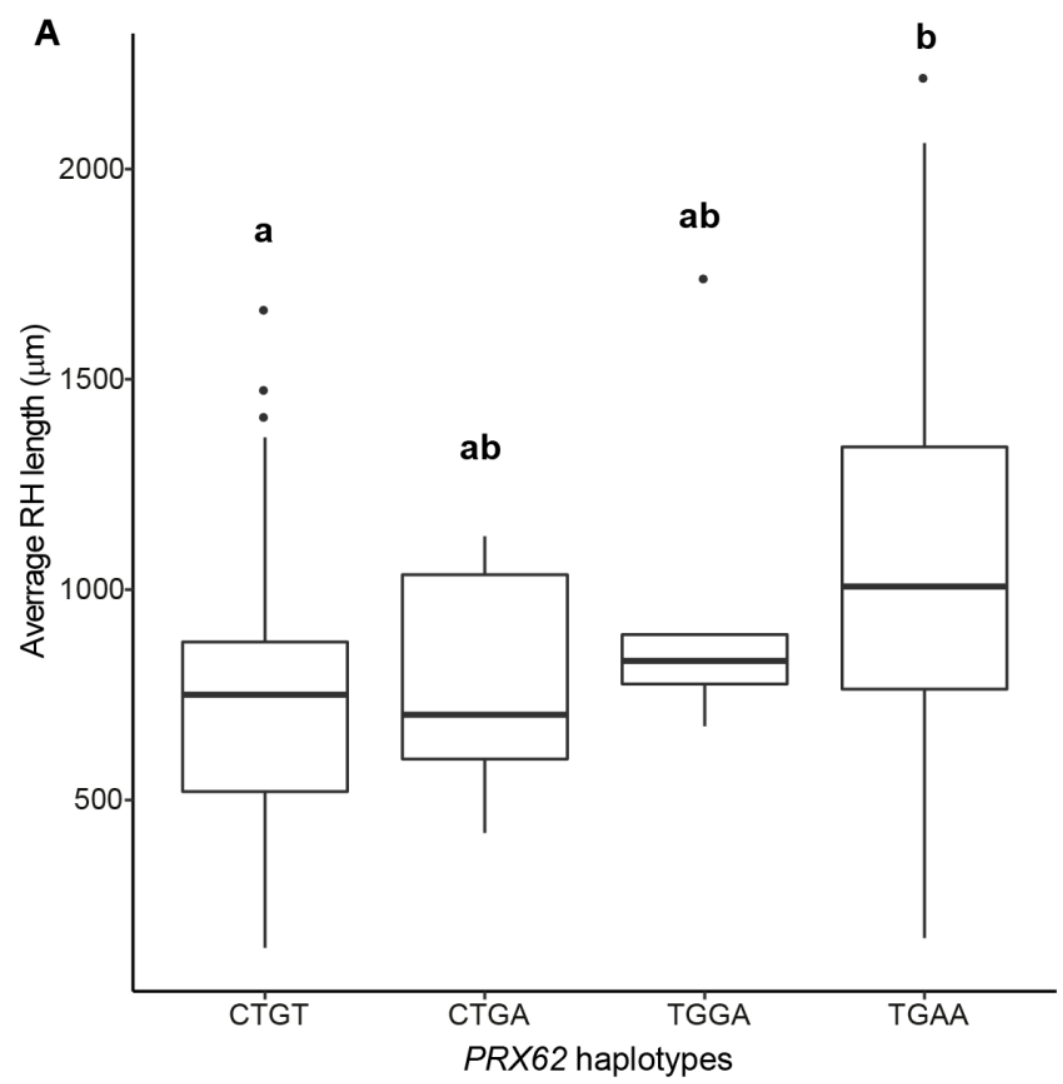

B ANOVA Table (Partial SS)

\begin{tabular}{l|ccccc} 
S.V. & SS & df & MS & F & $p$-value \\
\hline Model. & 2380630.12 & 3 & 793543.37 & 6.09 & 0.00074 \\
Haplotype & 2380630.12 & 3 & 793543.37 & 6.09 & 0.00074 \\
Error & 13411706.11 & 103 & 130210.74 & & \\
Total & 15792336.23 & 106 & & &
\end{tabular}

Test Tukey Alpha $=0.05 \quad$ LSD $=359.64070$

Error: 130210.74 df:103

\begin{tabular}{c|cccc} 
PRX62 haplotype & Means & $\mathrm{n}$ & \multicolumn{1}{c}{ S.E. } & \\
\hline CTGT & 725.33 & 79 & 40.6 & $\mathrm{a}$ \\
CTGA & 776.96 & 5 & 161.38 & $\mathrm{a} \mathrm{b}$ \\
TGGA & 983.32 & 5 & 161.38 & $\mathrm{a} \mathrm{b}$ \\
TGAA & 1113.79 & 18 & 85.05 & $\mathrm{~b}$
\end{tabular}

Figure S3. Haplotype analysis on PRX62 SNPs.

(A) Average $\mathrm{RH}$ length at $10^{\circ} \mathrm{C}$ was calculated for each informative haplotype (number of accessions carrying the haplotype $\geq 5$ ) obtained with the four highly associated SNPs identified by GWAS and localized in PRX62. Significant differences are indicated by different letters above each haplotype.

(B) Model details and contrast for one-way ANOVA. Haplotype contrasts were identified in a posthoc Tukey HSD test ( $p \leq 0.05$ ). Significant differences are indicated by different letters. 
PRX62 and PRX69 regulate RH growth at low-temperature

Short-RH

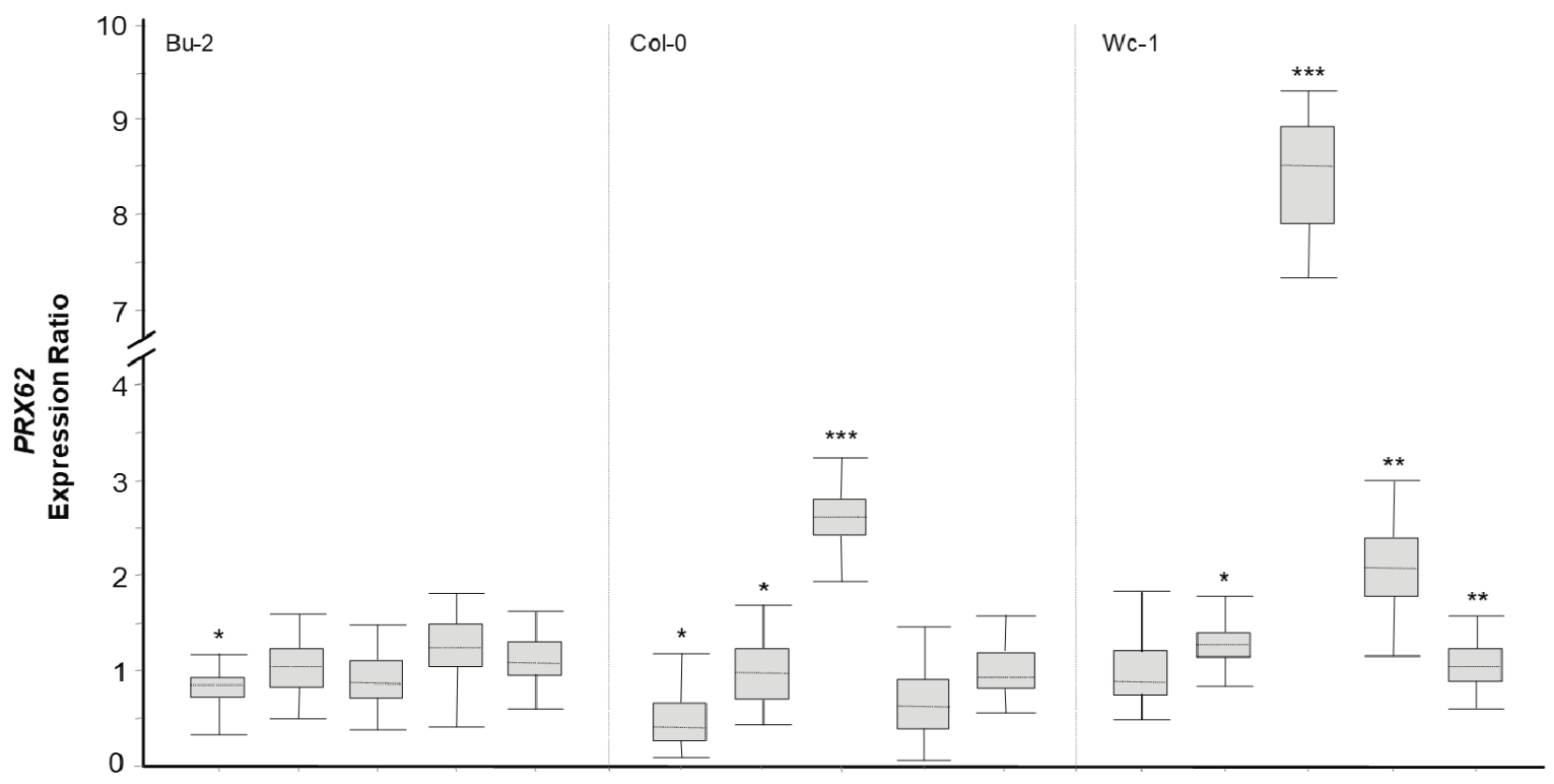

Figure S4. $P R X 62$, but not $P R X 69$, is differentially expressed at low-temperature $\left(10^{\circ} \mathrm{C}\right)$ in contrasting Arabidopsis accessions with contrasting RH phenotypes.

Expression measured by qPCR of $P R X 62$ and $P R X 69$ in three contrasting Arabidopsis accessions based on the $\mathrm{RH}$ phenotype detected at $10^{\circ} \mathrm{C}$. Total RNA was extracted from roots of in vitro plantlets (grown for 5 days at $22^{\circ} \mathrm{C}$ plus $6 \mathrm{~h}, 1$ day, 2 days, 3 days or 4 days either at $22^{\circ} \mathrm{C}$ or $10^{\circ} \mathrm{C}$ ). $P R X 62$ and $P R X 69$ transcript levels determined by RT-qPCR were normalized to ACT2 and UBQ1 as internal controls. Boxes represent the interquartile range. The dotted line symbolizes the median gene expression. Whiskers correspond to the minimum and maximum observations $(n=6)$. Asterisks indicate statistically significant differences between cold-treated and non-cold-treated groups $(* * *) P<0.001$, $\left({ }^{* *}\right) \mathrm{P}<0.01,\left({ }^{*}\right) \mathrm{P}<0.05$. 
PRX62 and PRX69 regulate RH growth at low-temperature

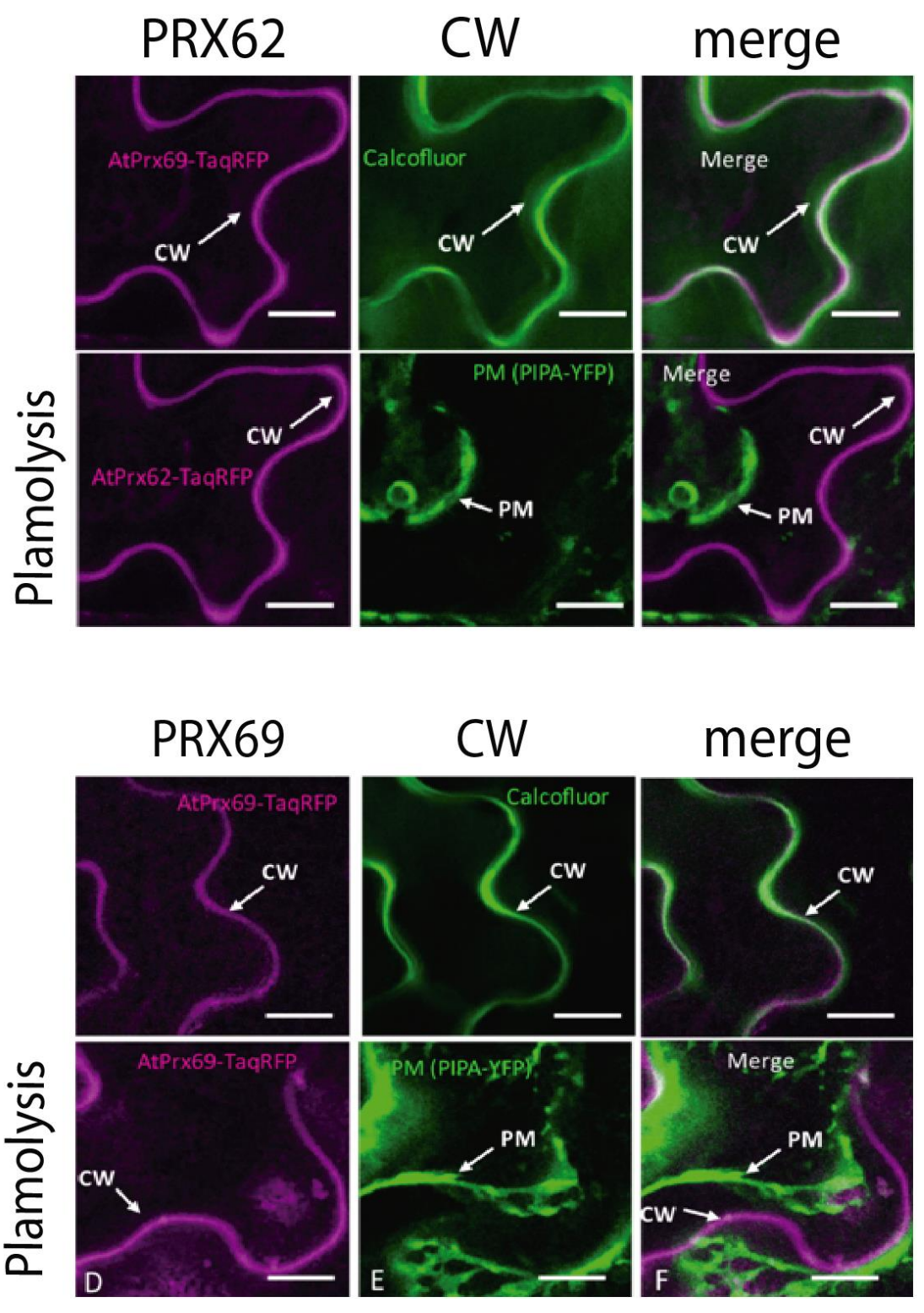

Figure S5. Apoplastic localization of PRX62 and PRX69.

Confocal laser scanning fluorescence signals from Nicotiana benthamiana plasmolyzed leaf epidermal cells co-expressing 35SproPRX62-TagRFP or 35SproPRX69-TagRFP (magenta channel, left panels) together with the plasma membrane marker Yellow fluorescent protein (YFP)-tagged Plasma Membrane Aquaporin (PIP2A-YFP) (green channel, central panels). Both channels merged (white signal, right panels). The top line corresponds to a single confocal section whereas the bottom line corresponds to the maximum intensity z projection of six confocal sections. Scale bars $=50 \mu \mathrm{m}$. $\mathrm{CW}=$ cell wall; $\mathrm{PM}=$ plasma membrane. 
PRX62 and PRX69 regulate RH growth at low-temperature
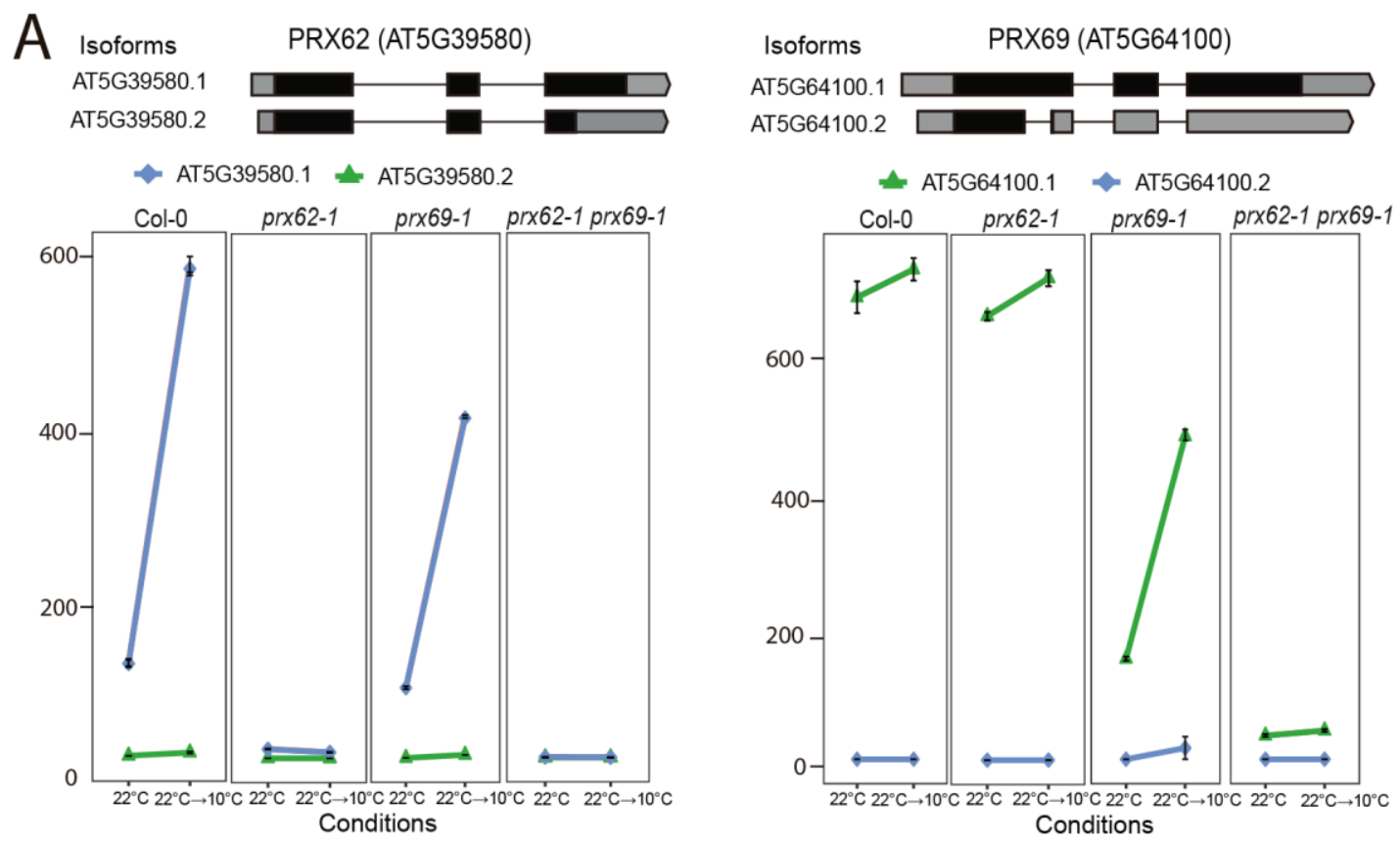

B
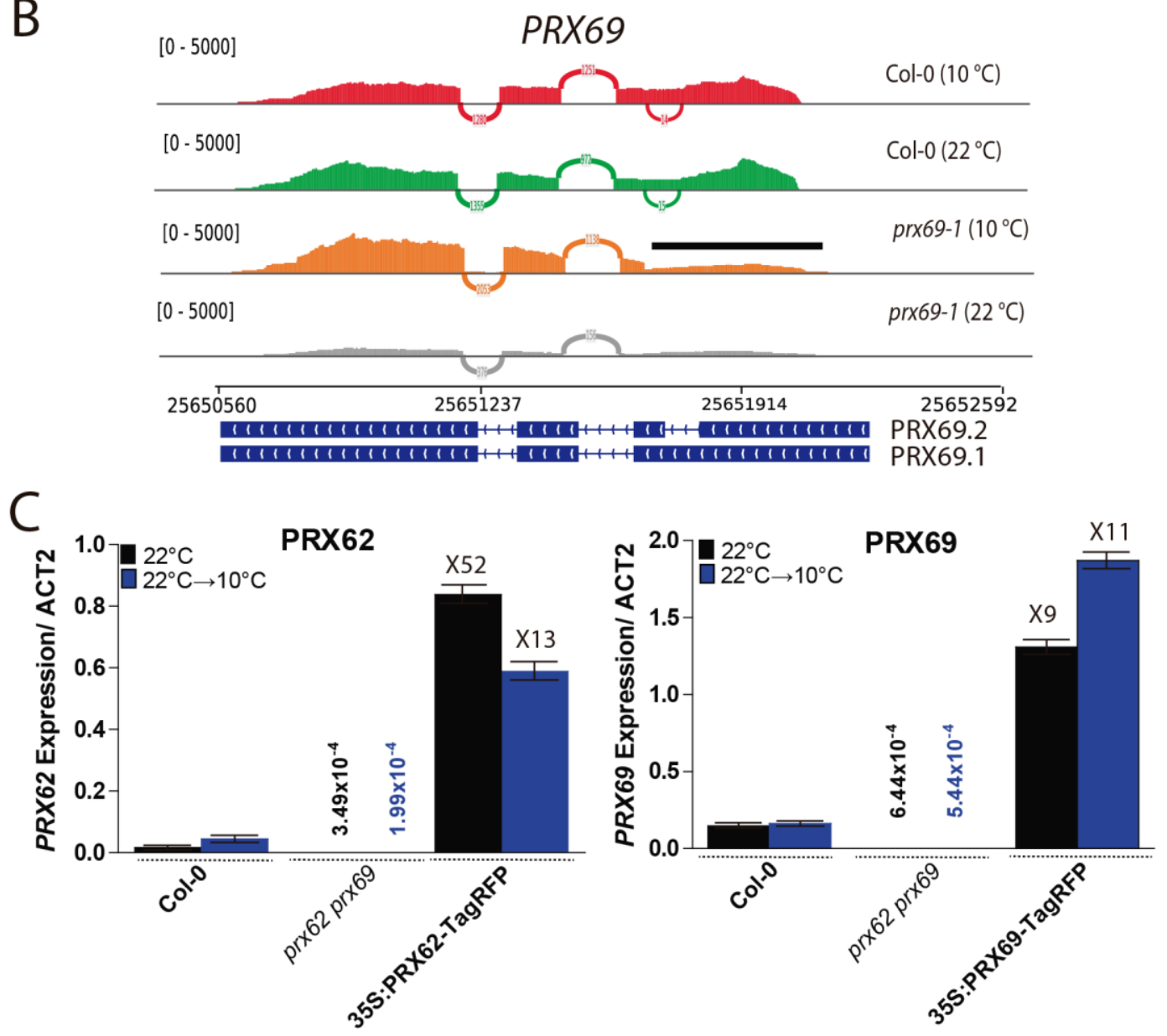

Figure S6. Expression analysis by RNA-seq and Real Time PCR of PRX62 and PRX69. 
PRX62 and PRX69 regulate RH growth at low-temperature

(A) Isoforms expression of PRX62 and PRX69 in Col-0, prx62-1, prx69-1 and prx62-1 prx69-1 double mutant determined by RNA-seq. Reads in PRX69 gene in prx69-1 mutant backgrounds showed a truncated version being expressed. Isoforms' schemes were adapted from boxify (https://boxify.boku.ac.at/). TPM = Transcripts Per Kilobase Million.

(B) Sashimi plots of PRX69 indicate the expression of a truncated RNA in the prx69-1 mutant. Sashimi plots (adapted from IGV) show the coverage for each alignment track (Col-0 and the prx69-1 mutant) plotted as a histogram; arcs represent splice junctions connecting exons. Alternative splicing isoforms for PRX69 are displayed below. The line on top of the graph highlights the region of the RNA that shows low coverage or low expression.

(C) Levels of $P R X 62$ and PRX69 expression in Col-0 roots, prx62-1 prx69-1 double mutant and overexpressor $P R X 62$ and $P R X 69$ lines. ACT2 was use as a housekeeping gene. Three biological replicates and three technical replicates per experiment were performed. 
PRX62 and PRX69 regulate RH growth at low-temperature

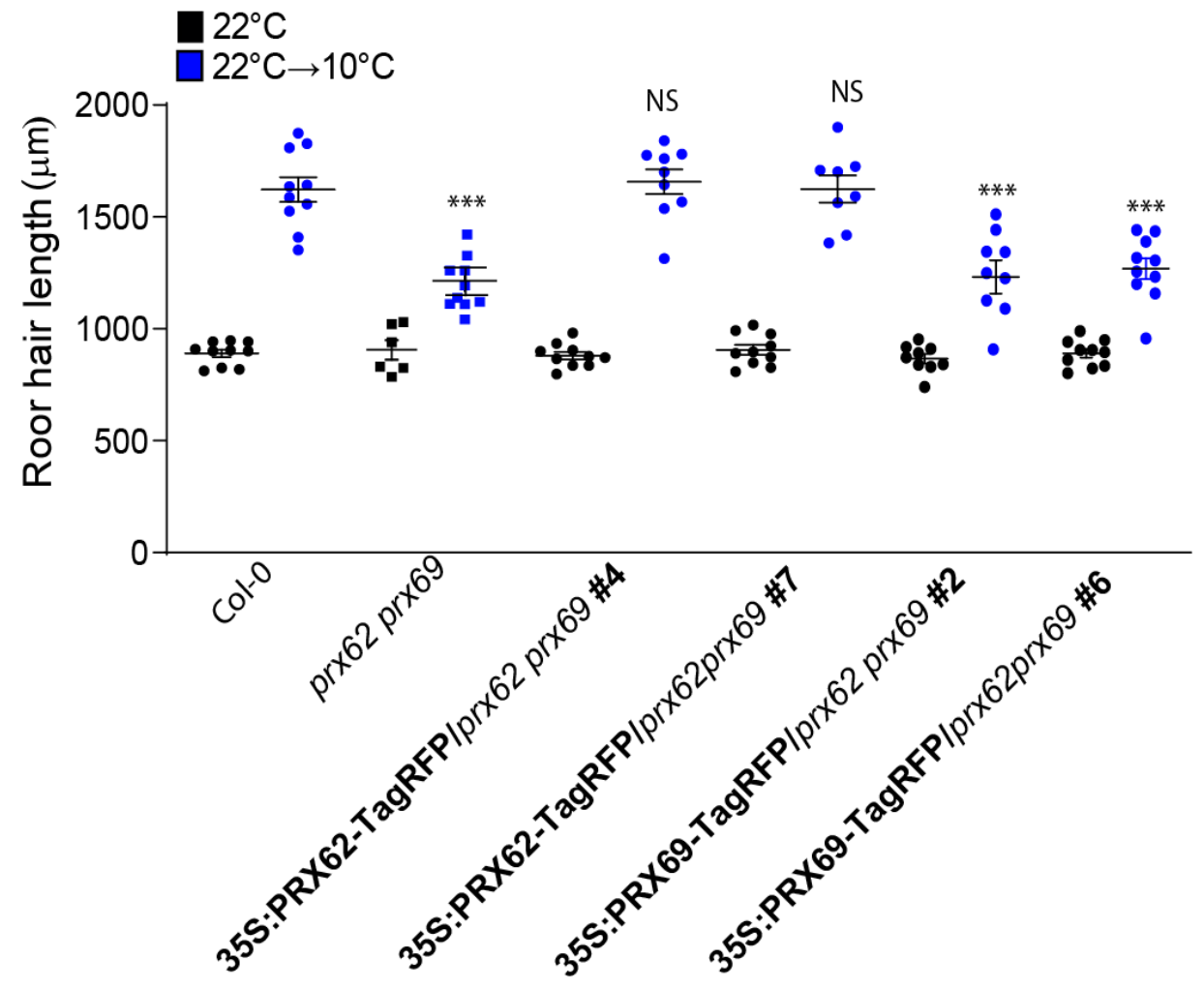

Figure S7. Phenotypic rescue of prx62 prx69 by overexpression of PRX62 or PRX69.

35SproPRX62 is able to rescue RH growth of prx62-1 prx69-1 double mutant while 35SproPRX69 failed to rescue of prx62-1 prx69-1 double mutant. $\mathrm{RH}$ length values are the mean of three replicates \pm SD. $\mathrm{P}$-value of one-way ANOVA, $(* * *) \mathrm{P}<0.001$. NS= no significant differences. 
bioRxiv preprint doi: https://doi.org/10.1101/2021.08.20.456256; this version posted August 20, 2021. The copyright holder for this preprint (which was not certified by peer review) is the author/funder, who has granted bioRxiv a license to display the preprint in perpetuity. It is made available under aCC-BY-NC-ND 4.0 International license.

PRX62 and PRX69 regulate $\mathrm{RH}$ growth at low-temperature

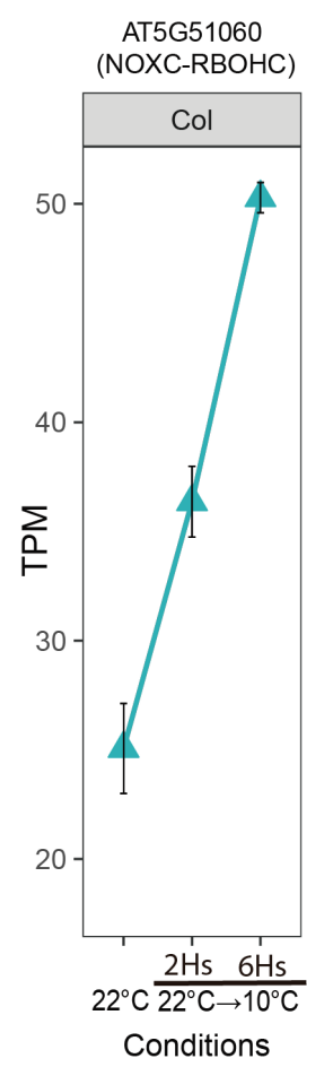

Figure S8. Expression of NOXC (RBOHC/RHD2) under low-temperature assessed by RNA-seq. TPM = Transcripts Per Kilobase Million. 
PRX62 and PRX69 regulate RH growth at low-temperature
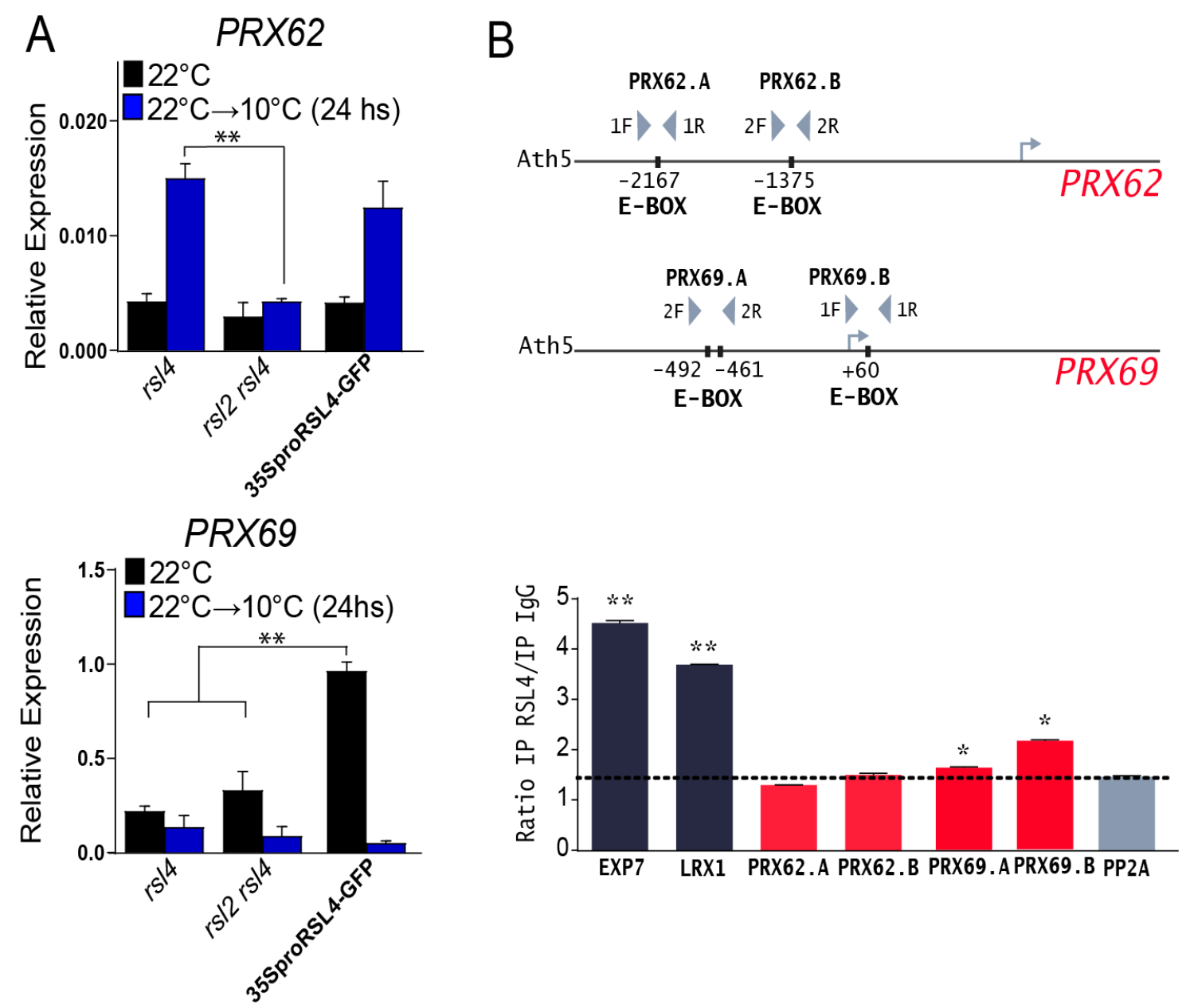

Figure S9. The transcription factor RSL4 controls the expression of PRX69.

(A) Expression analysis of $P R X 62$ and $P R X 69$ by qPCR in Col-0, $35 \mathrm{~S}_{\text {pro }} \mathrm{RSL} 4$, and in the mutants $r s / 4$, and $r s / 2 r s / 4$ grown at $22^{\circ} \mathrm{C}$ and then transferred for $24 \mathrm{hs}$ at low-temperature treatment $\left(10^{\circ} \mathrm{C}\right)$. Three biological replicates and three technical replicates per experiment were performed. P-value of oneway ANOVA, $(* *) \mathrm{P}<0.01$.

(B) ChIP analysis showing RSL4 binding to RHE-boxes elements (E-boxes) on the PRX62 and PRX69 promoter regions. The $P R X 62$ and PRX69 promoter regions (PPRXs), the relative positions of RHEboxes (E-boxes) and ChIP-PCR regions are indicated. The enrichment fold of RSL4-GFP in ChIP-PCR is shown for each region as a ratio with IgG IP taken as a negative control. The enrichment of each region was compared to $P P 2 A$ taken as a negative control and determining the background, indicated as a dotted line. EXP7 and $L R X 1$ were taken as positive controls according to Hwang et al. (2017). Significant differences are indicated when appropriate ( ${ }^{*} P<0.001,{ }^{*} P<0.01 ; t$ test). The experiment was performed three independent times showing the same trend. The graph represents two technical replicates of one of the independent experiments. $F=$ forward and $R=$ reverse primers. 
bioRxiv preprint doi: https://doi.org/10.1101/2021.08.20.456256; this version posted August 20, 2021. The copyright holder for this preprint (which was not certified by peer review) is the author/funder, who has granted bioRxiv a license to display the preprint in perpetuity. It is made available under aCC-BY-NC-ND 4.0 International license.

PRX62 and PRX69 regulate $\mathrm{RH}$ growth at low-temperature

Table S2. PRX62 and PRX69 are transcriptionally induced under low temperature.

\begin{tabular}{cccc}
\hline gene name & Log2 (WT 24h/WT Oh) & Gene FDR & Tissue expression \\
\hline PRX05 & 4,68 & $4,7 \mathrm{E}-21$ & endodermis-vascular \\
PRX04 & 3,31 & $1,5 \mathrm{E}-43$ & endodermis-vascular \\
PRX37 & 2,10 & $3,2 \mathrm{E}-15$ & endodermis-vascular \\
PRX62 & 2,04 & $6,2 \mathrm{E}-22$ & $\mathbf{R H}$ \\
PRX14 & 1,86 & $1,1 \mathrm{E}-05$ & endodermis-vascular \\
PRX69 & 1,76 & $1,4 \mathrm{E}-35$ & $\mathbf{R H}$ \\
\hline
\end{tabular}

FDR= False Discovery Rate. Extracted from Schlaen et al. (2015) where seedlings were grown at $22^{\circ} \mathrm{C}$ for 9 days and then transferred to $10^{\circ} \mathrm{C}$ for $24 \mathrm{hs}$. $\mathrm{RH}=$ root hair. 
bioRxiv preprint doi: https://doi.org/10.1101/2021.08.20.456256; this version posted August 20, 2021. The copyright holder for this preprint (which was not certified by peer review) is the author/funder, who has granted bioRxiv a license to display the preprint in perpetuity. It is made available under aCC-BY-NC-ND 4.0 International license.

PRX62 and PRX69 regulate $\mathrm{RH}$ growth at low-temperature

Table S3. Mutants and transgenic lines generated and used in this study.

\begin{tabular}{|c|c|c|}
\hline Transgenic line name & Gene construct/ mutant lines code & References \\
\hline prx62-1 & GK_287E07 & Jemmat et al. 2020 \\
\hline prx62-2 & SALK_151762 & Jemmat et al. 2020 \\
\hline prx69-1 & SAIL_691_G12 & Jemmat et al. 2020 \\
\hline prx69-2 & SALK_137991 & Jemmat et al. 2020 \\
\hline prx62-1prx69-1 & $\begin{array}{c}\text { prx62-1/GK_287E07 } \\
\text { prx69-1/SAIL_691_G12 }\end{array}$ & This study \\
\hline 35SproPRX62-TagRFP/Col-0 \#3 & 35Spromoter::PRX62-TagRFP & This study \\
\hline 35SproPRX62-TagRFP/Col-0 \#4 & 35Spromoter::PRX62-TagRFP & This study \\
\hline 35SproPRX69-TagRFP/Col-0 \#1 & 35Spromoter::PRX69-TagRFP & This study \\
\hline 35SproPRX69-TagRFP/Col-0 \#5 & 35Spromoter::PRX69-TagRFP & This study \\
\hline 35SproPRX62-TagRFP \#1/ prx62-1prx69-1 \#4 & $\begin{array}{l}\text { 35Spromoter::PRX62-TagRFP } \\
\text { / prx62-1prx69-1 }\end{array}$ & This study \\
\hline 35SproPRX69-TagRFP \#1/ prx62-1prx69-1 \#7 & $\begin{array}{l}\text { 35Spromoter::PRX69-TagRFP } \\
\text { / prx62-1prx69-1 }\end{array}$ & This study \\
\hline 35SproPRX69-TagRFP/ prx62-1prx69-1 \#2 & $\begin{array}{c}\text { 35Spromoter::PRX69-TagRFP \#1 } \\
\text { / prx62-1prx69-1 }\end{array}$ & This study \\
\hline 35SproPRX69-TagRFP/ prx62-1prx69-1 \#6 & $\begin{array}{c}\text { 35Spromoter::PRX69-TagRFP \#1 } \\
\text { / prx62-1prx69-1 }\end{array}$ & This study \\
\hline PRX62proGFP & PRX69promoter::GFP & This study \\
\hline PRX69proGFP & PRX62promoter::GFP & This study \\
\hline 35SproSS-TOMATO/Col-0 & $\begin{array}{l}\text { 35Spromoter::SS-TOMATO } \\
\text { /prx62-1prx69-1 }\end{array}$ & This study \\
\hline 35SproSS-TOMATO-EXT-LONG/Col-0 & $\begin{array}{l}\text { 35Spromoter::SS-TOMATO-EXT Long } \\
\text { /prx62-1prx69-1 }\end{array}$ & This study \\
\hline$r s / 4$ & $r s / 4-1$ & Yi et al. 2010 \\
\hline RSL4proGFP-RSL4 & RSL4promoter::GFP-RSL4 & Mangano et al. 2017 \\
\hline$r s / 2 r s / 4$ & $\begin{array}{c}r s / 2-1 / \text { SAIL_514C04 } \\
r s / 4-1\end{array}$ & Yi et al. 2010 \\
\hline 35SproRSL4 & 35Spromoter::RSL4 & Yi et al. 2010 \\
\hline
\end{tabular}


bioRxiv preprint doi: https://doi.org/10.1101/2021.08.20.456256; this version posted Auqust 20, 2021. The copyright holder for this preprint (which was not certified by peer review) is the author/funder, who has granted bioRxiv a license to display the preprint in perpetuity. It is made available under aCC-BY-NC-ND 4.0 International license.

PRX62 and PRX69 regulate $\mathrm{RH}$ growth at low-temperature

Table S4. List of Primers used in this study.

\begin{tabular}{|c|c|c|}
\hline Gene or Line & Primers Sequence $\left(5^{\prime}->3^{\prime}\right)$ & References \\
\hline \multicolumn{3}{|l|}{ genotyping by PCR } \\
\hline prx62-1 & $\begin{array}{l}\mathrm{F}=\mathrm{GATTACACACTATTAATTAGGAATTAGTTTG} \\
\mathrm{R}=\mathrm{GAGAGAAACCGAATCACGAG}\end{array}$ & Jemmat et al. 2020 \\
\hline prx62-2 & $\begin{array}{l}\mathrm{F}=\mathrm{GAGGAGGACACACGATC} \\
\mathrm{R}=\mathrm{AACGAAATTGAACTTTATTTATTCC}\end{array}$ & Jemmat et al. 2020 \\
\hline prx69-1 & $\begin{array}{l}\text { F= ATGGGTCGTGGTTACAATTTG } \\
\mathrm{R}=\text { CTTGACGTCACCTTCCTTAGG }\end{array}$ & Jemmat et al. 2020 \\
\hline prx69-2 & $\begin{array}{l}\mathrm{F}=\text { ATGGGTCGTGGTTACAATTTG } \\
\mathrm{R}=\mathrm{CTTGACGTCACCTTCCTTAGG}\end{array}$ & Jemmat et al. 2020 \\
\hline \multicolumn{3}{|l|}{ RT-qPCR } \\
\hline PRX62 & $\begin{array}{l}\mathrm{F}=\mathrm{TCGGACCACTGTGGCATCTCA} \\
\mathrm{R}=\mathrm{GAGTTAGGTCCCGATAAAAGCAC}\end{array}$ & This study \\
\hline PRX69 & $\begin{array}{l}\mathrm{F}=\text { CTGCTGGCTGCGGTCTAGTAA } \\
\mathrm{R}=\mathrm{ACTTCCCTCGTCTAACTCCACT}\end{array}$ & This study \\
\hline ACTIN 2 & $\begin{array}{l}\mathrm{F}=\text { GGTAACATTGTGCTCAGTGGTGG } \\
\mathrm{R}=\text { CTCGGCCTTGGAGATCCACATC }\end{array}$ & Fulton and Cobbett, 2003 \\
\hline 35SproPRXs-TagRFP & $\begin{array}{l}\text { PRX62 } \\
F=C C C A A G C T T A T G G G C T T G G T C C G A T \\
R=C G C G G A T C C G C A T T A A C C G C A G A G C \\
\text { PRX69 } \\
F=C C G G A A T T C A T G G G T C G T G G T T A C A \\
\text { R=CCGCCCGGGAGTTGATGGCGGAACA }\end{array}$ & This study \\
\hline \multicolumn{3}{|l|}{ CHIP } \\
\hline PRX62.1 F & AAGAAAATAAAGAGACGTTTTTGAACAG & This study \\
\hline PRX62.1 R & gggtattcggcttaaatacattttg & This study \\
\hline PRX62.2 F & ccaaactcgttcaggttatctagc & This study \\
\hline PRX62.2 R & atattggcgtcgaagcttaaaaga & This study \\
\hline PRX69.1 F & aaattcccataatttctgcgtcgtgtg & This study \\
\hline PRX69.1 R & GTTGTGTGTTTTGAGTTTGATGTTAAAGGG & This study \\
\hline PRX69.2 F & tatcgccacgtaactcattgatct & This study \\
\hline PRX69.2 R & tgtgattttgaaaaatataaacgcaaa & This study \\
\hline ChIP LRX1 F & TTTTTGTGACAGACATGCGTCC & This study \\
\hline ChIP LRX1 R & tcagccgtcaacgttaaatc & This study \\
\hline ChIP EXP7 F & aaatgtctgctgttcaatttaactaatc & This study \\
\hline ChIP EXP7 R & TGTTGTTTAAGTGAGGTTTTTGAATATAG & This study \\
\hline
\end{tabular}


PRX62 and PRX69 regulate RH growth at low-temperature

\section{REFERENCES}

Ariel, F. et al. R-Loop Mediated trans Action of the APOLO Long Noncoding RNA. Mol. Cell 77, 10551065.e4 (2020).

Barah, P. et al. Genome-scale cold stress response regulatory networks in ten Arabidopsis thaliana ecotypes. BMC Genomics 14, 1-16 (2013).

Bashline, L., Lei, L., Li, S. \& Gu, Y. Cell wall, cytoskeleton, and cell expansion in higher plants. Mol. Plant 7, 586-600 (2014).

Baumberger, N., Ringli, C. \& Keller, B. The chimeric leucine-rich repeat/extensin cell wall protein LRX1 is required for root hair morphogenesis in Arabidopsis thaliana. Genes Dev. 15, 1128-1139 (2001).

Baumberger, N., Steiner, M., Ryser, U., Keller, B. \& Ringli, C. Synergistic interaction of the two paralogous Arabidopsis genes LRX1 and LRX2 in cell wall formation during root hair development. Plant J. 35, 71-81 (2003).

Benjamini, Y. \& Yekutieli, D. The Control of the False Discovery Rate in Multiple Testing under Dependency. Ann. Stat. 29, 1165-1188 (2001).

Benjamini, Y. \& Hochberg, Y. Controlling the False Discovery Rate: A Practical and Powerful Approach to Multiple Testing. J. R. Stat. Soc. Ser. B 57, 289-300 (1995).

Bernards, M. A. et al. Biochemical characterization of the suberization-associated anionic peroxidase of potato. Plant Physiol. 121, 135-46 (1999).

Bhosale, R. et al. A mechanistic framework for auxin dependent Arabidopsis root hair elongation to low external phosphate. Nat. Commun. 9, 1-9 (2018).

Bidhendi, A. J. \& Geitmann, A. Relating the mechanics of the primary plant cell wall to morphogenesis. J. Exp. Bot. 67, 449-61 (2016).

Bourbousse, C., Vegesna, N. \& Law, J. A. SOG1 activator and MYB3R repressors regulate a complex DNA damage network in Arabidopsis. Proc. Natl. Acad. Sci. U. S. A. 115, E12453-E12462 (2018).

Bullard, J. H., Purdom, E., Hansen, K. D. \& Dudoit, S. Evaluation of statistical methods for normalization and differential expression in mRNA-Seq experiments. BMC Bioinformatics 11, 113 (2010).

Calixto, C. P. G. et al. Rapid and dynamic alternative splicing impacts the arabidopsis cold response transcriptome[CC-BY]. Plant Cell 30, 1424-1444 (2018).

Cannon, M. C. et al. Self-assembly of the plant cell wall requires an extensin scaffold. Proc. Natl. Acad. Sci. U. S. A. 105, 2226-2231 (2008).

Chapman, J. M., Muhlemann, J. K., Gayomba, S. R. \& Muday, G. K. RBOH-Dependent ROS Synthesis and ROS Scavenging by Plant Specialized Metabolites to Modulate Plant Development and Stress Responses. Chemical Research in Toxicology vol. 32 370-396 (2019).

Cosio, C. et al. The class III peroxidase PRX17 is a direct target of the MADS-box transcription factor AGAMOUS-LIKE15 (AGL15) and participates in lignified tissue formation. New Phytol. 213, 250263 (2017).

Datta, S., Prescott, H. \& Dolan, L. Intensity of a pulse of RSL4 transcription factor synthesis determines Arabidopsis root hair cell size. Nat. Plants 1, 1-6 (2015).

Di Rienzo J.A., Casanoves F., Balzarini M.G., Gonzalez L., Tablada M., R. C. W. InfoStat, versión 2008, Grupo InfoStat, FCA, Universidad Nacional de Córdoba, Argentina. (2008).

Ding, Y., Shi, Y. \& Yang, S. Advances and challenges in uncovering cold tolerance regulatory mechanisms in plants. New Phytologist vol. 222 1690-1704 (2019). 
PRX62 and PRX69 regulate RH growth at low-temperature

Ding, Y., Shi, Y. \& Yang, S. Molecular Regulation of Plant Responses to Environmental Temperatures. Molecular Plant vol. 13 544-564 (2020).

Dong, W., Kieliszewski, M. \& Held, M. A. Identification of the pl 4.6 extensin peroxidase from Lycopersicon esculentum using proteomics and reverse-genomics. Phytochemistry 112, 151-159 (2015).

Dvořák, P., Krasylenko, Y., Zeiner, A., Šamaj, J. \& Takáč, T. Signaling Toward Reactive Oxygen SpeciesScavenging Enzymes in Plants. Frontiers in Plant Science vol. 112178 (2021).

Dunand, C., Crèvecoeur, M. \& Penel, C. Distribution of superoxide and hydrogen peroxide in Arabidopsis root and their influence on root development: Possible interaction with peroxidases. New Phytol. 174, 332-341 (2007).

Fabrice, T. N. et al. LRX proteins play a crucial role in pollen grain and pollen tube cell wall development. Plant Physiol. 176, 1981-1992 (2018).

Francoz, E. et al. Pectin Demethylesterification Generates Platforms that Anchor Peroxidases to Remodel Plant Cell Wall Domains. Dev. Cell 48, 261-276.e8 (2019).

Guo, W. et al. 3D RNA-seq: a powerful and flexible tool for rapid and accurate differential expression and alternative splicing analysis of RNA-seq data for biologists. RNA Biol. (2020) doi:10.1080/15476286.2020.1858253.

Hannah, M. A., Heyer, A. G. \& Hincha, D. K. A global survey of gene regulation during cold acclimation in Arabidopsis thaliana. PLoS Genet. 1, e26 (2005).

Horton, M. W. et al. Genome-wide patterns of genetic variation in worldwide Arabidopsis thaliana accessions from the RegMap panel. Nat. Genet. 44, 212-216 (2012).

Hossain, M. S. et al. Divergent cytosine DNA methylation patterns in single-cell, soybean root hairs. New Phytol. 214, 808-819 (2017).

Hwang, Y., Choi, H. S., Cho, H. M. \& Cho, H. T. Tracheophytes contain conserved orthologs of a basic helix-loop-helix transcription factor that modulate ROOT HAIR SPECIFIC genes. Plant Cell 29, 3953 (2017).

Jackson, P. A. P. et al. Rapid deposition of extensin during the elicitation of grapevine callus cultures is specifically catalyzed by a 40-kilodalton peroxidase. Plant Physiol. 127, 1065-1076 (2001).

Jacobowitz, J. R., Doyle, W. C. \& Weng, J.-K. PRX9 and PRX40 Are Extensin Peroxidases Essential for Maintaining Tapetum and Microspore Cell Wall Integrity during Arabidopsis Anther Development. Plant Cell 31, 848-861 (2019).

Jemmat, A. M. et al. Coordination of five class III peroxidase-encoding genes for early germination events of Arabidopsis thaliana. Plant Sci. 298, 110565 (2020).

Kang, H. M. et al. Efficient Control of Population Structure in Model Organism Association Mapping. Genetics 178, 1709-1723 (2008).

Kang, H. M. et al. Variance component model to account for sample structure in genome-wide association studies. Nat. Genet. 42, 348-354 (2010).

Karimi, M., Inzé, D. \& Depicker, A. GATEWAYTM vectors for Agrobacterium-mediated plant transformation. Trends in Plant Science vol. 7 193-195 (2002).

Kim, B. H., Kim, S. Y. \& Nam, K. H. Genes encoding plant-specific class III peroxidases are responsible for increased cold tolerance of the brassinosteroid-insensitive 1 mutant. Mol. Cells 34, 539-548 (2012).

Kwon, T. et al. Transcriptional response of Arabidopsis seedlings during spaceflight reveals peroxidase 
PRX62 and PRX69 regulate $\mathrm{RH}$ growth at low-temperature

and cell wall remodeling genes associated with root hair development. Am. J. Bot. 102, 21-35 (2015).

Law, C. W., Chen, Y., Shi, W. \& Smyth, G. K. Voom: Precision weights unlock linear model analysis tools for RNA-seq read counts. Genome Biol. 15, 1-17 (2014).

Lee, R. D. W. \& Cho, H.-T. Auxin, the organizer of the hormonal/environmental signals for root hair growth. Front. Plant Sci. 4, (2013).Mangano, S. et al. Molecular link between auxin and ROSmediated polar growth. Proc. Natl. Acad. Sci. U. S. A. 114, 5289-5294 (2017).

Lee, Y., Rubio, M. C., Alassimone, J. \& Geldner, N. A mechanism for localized lignin deposition in the endodermis. Cell 153, 402-412 (2013).

Lee, Y., Yoon, T.H., Lee, J., Jeon, S.Y., Lee, J.H., Lee, M.K., Chen, H.Z., Yun, J., Oh, S.Y., Wen, X.H., et al. (2018). A lignin molecular brace controls precision processing of cell walls critical for surface integrity in Arabidopsis. Cell 173, 1468-1480.e9.

Leuendorf, J. E., Frank, M. \& Schmülling, T. Acclimation, priming and memory in the response of Arabidopsis thaliana seedlings to cold stress. Sci. Rep. 10, 689 (2020).

Mangano, S., Denita-Juarez, S. P., Marzol, E., Borassi, C. \& Estevez, J. M. High Auxin and High Phosphate Impact on RSL2 Expression and ROS-Homeostasis Linked to Root Hair Growth in Arabidopsis thaliana. Front. Plant Sci. 9, 1-8 (2018).

Maruyama, K. et al. Identification of cold-inducible downstream genes of the Arabidopsis DREB1A/CBF3 transcriptional factor using two microarray systems. Plant J. 38, 982-993 (2004).

Marzol, E. et al. PRX01, PRX44, and PRX73 are class-III extensin-related peroxidases that modulates root hair growth in Arabidopsis thaliana. bioRxiv 2020.02.04.932376 (2020) doi:10.1101/2020.02.04.932376.

Marzol, E. et al. Filling the Gaps to Solve the Extensin Puzzle. Mol. Plant 11, 645-658 (2018). Mol Plant. 11(5):645-658.

Moison, M. et al. The IncRNA APOLO interacts with the transcription factor WRKY42 to trigger root hair cell expansion in response to cold. Mol. Plant 0, (2021).

Nakagawa, T. et al. Development of series of gateway binary vectors, pGWBs, for realizing efficient construction of fusion genes for plant transformation. J. Biosci. Bioeng. 104, 34-41 (2007).

Nurhasanah Ritonga, F. \& Chen, S. Physiological and molecular mechanism involved in cold stress tolerance in plants. Plants vol. 9560 (2020).

Orman-Ligeza, B. et al. RBOH-mediated ROS production facilitates lateral root emergence in Arabidopsis. Development 143, 3328-39 (2016).

Pacheco, J. M. et al. The IncRNA APOLO and the transcription factor WRKY42 target common cell wall EXTENSIN encoding genes to trigger root hair cell elongation. Plant Signal. Behav. 16, 1920191 (2021).

Passardi, F., Longet, D., Penel, C. \& Dunand, C. The class III peroxidase multigenic family in rice and its evolution in land plants. Phytochemistry 65, 1879-1893 (2004).

Passardi, F., Penel, C. \& Dunand, C. Performing the paradoxical: How plant peroxidases modify the cell wall. Trends in Plant Science vol. 9 534-540 (2004).

Patro, R., Duggal, G., Love, M. I., Irizarry, R. A. \& Kingsford, C. Salmon provides fast and bias-aware quantification of transcript expression. Nat. Methods 14, 417-419 (2017).

Penfield, S. Temperature perception and signal transduction in plants. New Phytologist vol. 179 615628 (2008).Quint, M. et al. Molecular and genetic control of plant thermomorphogenesis. Nature 
PRX62 and PRX69 regulate RH growth at low-temperature

Plants vol. 2 (2016).

Pereira, C. S. et al. Extensin network formation in Vitis vinifera callus cells is an essential and causal event in rapid and $\mathrm{H} 2 \mathrm{O} 2$-induced reduction in primary cell wall hydration. BMC Plant Biol. 11, 106 (2011).

Pfaffl, M. W. A new mathematical model for relative quantification in real-time RT-PCR. Nucleic Acids Res. 29, 45e- 45 (2001).

Pfaffl, M. W., Horgan, G. W. \& Dempfle, L. Relative expression software tool (REST) for group-wise comparison and statistical analysis of relative expression results in real-time PCR. Nucleic Acids Res. 30, 36e - 36 (2002).

Price, N. J. et al. A Biochemical and Molecular Characterization of LEP1, an Extensin Peroxidase from Lupin. J. Biol. Chem. 278, 41389-41399 (2003).

Ringli, C. The hydroxyproline-rich glycoprotein domain of the Arabidopsis LRX1 requires Tyr for function but not for insolubilization in the cell wall. Plant J. 63, 662-669 (2010).

Ritchie, M. E. et al. Limma powers differential expression analyses for RNA-sequencing and microarray studies. Nucleic Acids Res. 43, e47 (2015).

Saraçli, S., Doğan, N. \& Doğan, I. Comparison of hierarchical cluster analysis methods by cophenetic correlation. J. Inequalities Appl. 2013, 1-8 (2013).

Schlaen, R. G. et al. The spliceosome assembly factor GEMIN2 attenuates the effects of temperature on alternative splicing and circadian rhythms. Proc. Natl. Acad. Sci. U. S. A. 112, 9382-9387 (2015).

Schnabelrauch, L. S., Kieliszewski, M., Upham, B. L., Alizedeh, H. \& Lamport, D. T. A. Isolation of pl 4.6 extensin peroxidase from tomato cell suspension cultures and identification of Val-Tyr-Lys as putative intermolecular cross-link site. Plant J. 9, 477-489 (1996).

Sede, A. R. et al. Arabidopsis pollen extensins LRX are required for cell wall integrity during pollen tube growth. FEBS Lett. 592, 233-243 (2018).

Seren, Ü. et al. GWAPP: A Web Application for Genome-Wide Association Mapping in Arabidopsis. Plant Cell 24, 4793-4805 (2012).

Shin, J. H., Blay, S., McNeney, B. \& Graham, J. LDheatmap: An R function for graphical display of pairwise linkage disequilibria between single nucleotide polymorphisms. J. Stat. Softw. 16, 1-9 (2006).

Soneson, C., Love, M. I. \& Robinson, M. D. Differential analyses for RNA-seq: Transcript-level estimates improve gene-level inferences. F1000Research 4, 1521 (2016).

Srivastava, L. M. Cell Wall, Cell Division, and Cell Growth. in Plant Growth and Development 23-74 (Elsevier, 2002). doi:10.1016/b978-012660570-9/50142-8.

Turner, S. Qqman: Q-Q and Manhattan Plots for GWAS Data. R Package Version 0.1.8. 5 https://cran.r-project.org/package=qqman (2021).

Valdés-López, O. et al. Soybean roots grown under heat stress show global changes in their transcriptional and proteomic profiles. Front. Plant Sci. 7, 517 (2016).

Valério, L., De Meyer, M., Penel, C. \& Dunand, C. Expression analysis of the Arabidopsis peroxidase multigenic family. Phytochemistry 65, 1331-1342 (2004).

Velasquez, S. M. et al. Low Sugar Is Not Always Good: Impact of Specific O -Glycan Defects on Tip Growth in Arabidopsis. Plant Physiol. 168, 808-813 (2015).

Velasquez, S. M. et al. O-glycosylated cell wall proteins are essential in root hair growth. Science (80.). 332, 1401-1403 (2011). 
PRX62 and PRX69 regulate RH growth at low-temperature

Waese, J. et al. ePlant: Visualizing and exploring multiple levels of data for hypothesis generation in plant biology. Plant Cell 29, 1806-1821 (2017).

Wang, X. et al. Pollen-expressed leucine-rich repeat extensins are essential for pollen germination and growth. Plant Physiol. 176, 1993-2006 (2018).

Wojtaszek, P., Trethowan, J. \& Bolwell, G. P. Reconstitution in vitro of the components and conditions required for the oxidative cross-linking of extracellular proteins in French bean (Phaseolus vulgaris L.). FEBS Lett. 405, 95-98 (1997).

Yaqoob, A. et al. Dual functions of Expansin in cell wall extension and compression during cotton fiber development. Biologia (Bratisl). 75, 2093-2101 (2020).

Yi, K., Menand, B., Bell, E. \& Dolan, L. A basic helix-loop-helix transcription factor controls cell growth and size in root hairs. Nat. Genet. 42, 264-267 (2010).

Zhang, S. et al. Multiple phytohormones promote root hair elongation by regulating a similar set of genes in the root epidermis in Arabidopsis. J. Exp. Bot. 67, 6363-6372 (2016).

Zhang, Z. et al. Mixed linear model approach adapted for genome-wide association studies. Nat. Genet. 42, 355-360 (2010).

Zhang, R. et al. A high quality Arabidopsis transcriptome for accurate transcript-level analysis of alternative splicing. Nucleic Acids Res. 45, 5061-5073 (2017). 